\title{
Transport Analytics in action: A Cloud-based Decision Support System for efficient City Bus Transportation
}

\author{
M Mathirajan ${ }^{1 \neq}$, Rajesh Devadas $^{1}$ and Ramakrishnan Ramanthan ${ }^{2}$ \\ ${ }^{1}$ Department of Management Studies \\ Indian Institute of Science \\ Bangalore 560012 \\ Email: iiscmathi@gmail.com / rajesh.devadas@gmail.com
}

${ }^{2}$ Business and Management Research Institute

University of Bedfordshire

Room No. 221, Putteridge Bury Campus

Hitchin Road, Luton LU2 8LE, Bedfordshire

Email: ram.ramanathan@beds.ac.uk

\begin{abstract}
Optimising city bus transport operations helps conserve fuel by providing the urban transport service as efficiently as possible. This study develops a Cloud-based Decision Support System (C-DSS) for transport analytics. The C-DSS is based on an intelligent model on location of depots for opening new depots and/or closing a few existing depots and allocation of city-buses to depots. The CDSS is built on the Cloud Computing architecture with three layers and includes an efficient and simple greedy heuristic algorithm. Using modern information and communications technology tools, the proposed C-DSS minimizes the cost of city bus transport operations and in turn to reduce fuel consumption and $\mathrm{CO}_{2}$ emissions in urban passenger transport. The proposed C-DSS is demonstrated for its workability and evaluated for its performance on 25 large scale pseudo data generated based on the observation from Bangalore Metropolitan Transport Corporation (BMTC) in India.
\end{abstract}

Subject Classification: decision: 7: 90B50 Management decision making / heuristics: 1: 68T20 Problem solving / decision: 6: 68U35 Information systems (

Keyword: City Bus Transport, Urban road transportation system, heuristic optimization, Decision Support Systems (DSS), Cloud-based DSS

* Corresponding Author 


\section{Introduction}

Continuously every urban city is getting more and more crowded and the need of personal mobility is continuously increasing. In addition, as the urban city is continuously growing the decisiondimensions of the urban road transportation systems (URTS) and the interaction between these decision-dimensions and the socioeconomic system have increased by many folds. In India, these URTS are generally managed by Road Transport Corporations or Undertakings controlled by the Government. Each such organization is endowed with thousands of buses, thousands of crew and personnel, and passenger demand arising at different points of time in several directions. Associative with these are many decision problems such as rationalization of routes, scheduling of vehicles, crew scheduling, system oriented planning and designing of the transportation network, passenger oriented transportation system, traffic control and management, location of depots for opening new depots and/or closing a few existing depots, assignment of buses to depots for maintenance, fleet and crew sizing, vehicle assignment and scheduling, etc., and these need to be addressed at appropriate time and in a continuous interval for enhancing the flexibility of URTS. The most commonly cited objectives of URTS are efficiency in the use of resources, improved accessibility, environmental protection, and increased safety. To reach these objectives different descriptive, predictive and prescriptive analytics, such as forecasting, simulation, resource optimization models/techniques, etc., have been considered.

However, analysis of the literature, particularly in Indian scenarios, highlighted that modern transport planning professionals are no longer capable of solving ever increasing dynamic complex problems associated with URTS using traditional methods being followed in URTS and the required resources existing in the URTS. Analysis of the literature also indicated that considering the advantages of analytics such as heuristic optimization, and decision science along with modern Information and Communication Technologies (ICT) such as Geographical Information System (GIS), Intelligent Transport Systems (ITS), problem specific Decision Support System (DSS), Web and Internet, Cloud Computing and smart solutions would facilitate the transport planning professionals in better decision making. In addition to utilizing the power of today's analytics for analyzing collected data to solve the problem, some new approaches, which take decision maker behavior into consideration, have been added to transport planners' tools for getting a set of solutions with a comparative list of advantages instead of single solution. More generally, today, it is safe to say that the design and management of transportation systems of every URTS need to exploit every possible advanced and innovative Information and Technology (IT) based technique for continuous system performance. Importantly, analytics is a field which provides such techniques with today's power ICT such as cloud computing.

However, even today, the utilities of Information and Communication Technologies (ICT) and analytics in Indian URTS particularly for decision making issues are very limited. This could be due 
to the additional cost required for introducing ICT and the analytics tools as well as additional requirements of specific experts with ICT and Analytics background. With this backdrop, this study attempts to support the Indian URTS by developing a Cloud based Decision Support Systems (CDSS), without newly introducing ICT, analytics tools and specific experts in URTS for minimizing the cost of the bus operations. Particularly, this study proposes a cloud-based Decision Support System for one of the important complex strategic / tactical decision problems, addressed by Mathirajan et al. [28], as this decision problem has impacts on social, economic, and development aspects of URTS. Particularly, the proposed C-DSS allows the decision maker for carrying out different what-if analyses and heuristically optimizing the decision problem on (a) allocation of buses to depots with an objective of minimizing the total dead-kilometer cost, and/or (b) an integrated decision problem on opening new depots and/or closing a few existing depots along with allocation of city-buses to depots to optimize the cost of operations by minimizing the sum of dead-kilometer cost, total capital cost due to introducing new depots, and total salvage cost by eliminating existing depots.

The novelties of the proposed prototype C-DSS is that the DSS cloud and Web service-based architecture is easy to manage as well as to update and able to provide flexibility in information exchange operations among the cooperative partners. In this context, the proposed C-DSS acts as an independent entity that collects all the relevant data and provides decisions to the decision maker, for improving the performances, and thus improving the specific objective of minimizing the cost of bus operations.

The organization of the paper is structured as follows: Section 2 describes briefly the real-life problem considered in this study on Location of Depots and Allocation of Buses to Depots (LD-ABD) observed in Indian URTS. Subsequently, closely related literature review is carried out in section 3. The development of the proposed prototype C-DSS for LD-ABD problem along with testing and verification are discussed in Section 4. The external validation of the proposed C-DSS, carried out, is presented in section 5 . The section 5 presents the discussion of the present study. Finally, contribution of the study with implications, limitations and future research are outlined in Section 7.

\section{Problem Statement and Objective}

The use of data-based decision making for transport - also called transport analytics - requires sophisticated ICT and decision support (Harris et al., [12]). In line with this trend, this paper builds on the transport analytics model developed in a previously published research article (Mathirajan et al., [28]). The main objective of this study is to develop a Cloud based Decision Support System (C-DSS) for an important real life transport analytics problem on optimal/efficient Location of Depots (LD) and Allocation of Buses to Depots (ABD), defined in Mathirajan et al. [28], with an objective of optimizing the cost of operation, particularly to minimize the sum of the total (a) dead-kilometre cost, 
(b) fixed cost associated with introducing new depots, and (c) salvage value due to closing the depots.

The research problem considered for developing C-DSS is succinctly stated below but readers interested in knowing more about it should refer to Mathirajan et al. [28].

We are given a set of $\mathbf{n}_{1}$ existing number of buses, $\mathbf{n}_{2}$ number of new buses/routes to be included in the existing URTS services due to increased population and city sizes, and $\mathbf{N}$ (= $\mathbf{n}_{1}+\mathbf{n}_{2}$ ) be the total number of buses available for optimally/efficiently allocating to the available depots. We are also given a set of $\mathbf{m}_{\mathbf{1}}$ existing number of depots, number of maximum existing depots $\mathbf{m}_{2}$ (and $\mathbf{m}_{2}<\mathbf{m}_{1}$ ) for possible to close, and exact number of existing depots $\mathbf{m}_{\mathbf{3}}$ (and $\mathbf{m}_{3}<\mathbf{m}_{\mathbf{2}}$ ) to be closed. In addition, we are given a set of maximum number of new locations for new depots $\mathbf{m}_{\mathbf{4}}$ for the possibility of opening, and exact number of new depots $\mathbf{m}_{5}$ (and $\mathbf{m}_{5}<\mathbf{m}_{4}$ ) to be opened with available budget $\mathbf{b}$ for opening new depots. Considering the closing possibility of the existing depots and opening possibility of new locations, we are having a set of total number of available depots Mfor allocation of given number of buses (and $\mathbf{M}=\mathbf{m}_{1}+\mathbf{m}_{4}$ ) with depot capacity $\mathbf{C A P}_{\mathbf{j}}$ $(\mathbf{j}=\mathbf{1 , 2}$...M depots). Finally, the values of the additional required parameters: Fixed cost $\mathbf{F C}_{\mathbf{j}}$ associated with opening of new depot ' $\mathrm{j}$ ', Salvage $\operatorname{cost} \mathbf{S} \mathbf{C}_{\mathbf{j}}$ associated with closing the existing depot ' $\mathrm{j}$ ', and dead kilometre cost $\mathbf{C}_{\mathbf{i j}}$ if bus ' $\mathrm{i}$ ' ( $\mathbf{i = 1 , 2 . . . . N )}$ ) is allocated to depot ' $\mathrm{j}$ ' $(\mathbf{j}=\mathbf{1 , 2}$...M depots) are also given. With these given data the objective is to propose a $\mathrm{C}$ DSS to decide optimal/efficient choice of the depots for both opening and closing as well as allocation of buses to the depots for minimizing the sum of dead-kilometer cost, total capital cost due to introducing new depots, and total salvage cost by eliminating existing depots along with the assumptions defined in Mathirajan et al (2018).

\section{Related Work}

The closely related existing literatures are grouped into (a) the research problem considered for proposing the C-DSS and (b) the current status of DSS in general and C-DSS in particular for the research problem considered in this study and the same are discussed as follows:

There are various studies in the literature addressing operational level to strategic level decision problems associated with URTS. The recent review paper by Ibarra-Rojas et al. [15] nicely consolidated various decision problems related to URTS addressed in the literature. In addition, there are various studies (Guihaire and Hao [11]; Kepatsoglou and Karlaftis, [19]; Farahani, et al. [10]; Arbex and Cunha, [4]) addresses on transit (depot) network design problem associated with URTS. Surprisingly there is no explicit literature analysis in the review study carried out by Guihaire and Hao [11], and Ibarra-Rojas et al. [15] on the decisions problem related to (i) allocation of buses to depots (ABD), and (ii) location of depots and allocation of buses to depots (LD-ABD) with an objective of minimizing total dead kilometer cost and in turn minimizing fuel consumptions as well as $\mathrm{CO}_{2}$. However, for a brief analysis of the literature on these decision problems, the interested reader can refer Mathirajan et al. [28]. Furthermore, from the analysis of the earlier research on ABD and LD$\mathrm{ABD}$ problems, all the existing studies are focused to the development of mathematical and or heuristic optimization model with validation of the proposed model(s) either using real-life data or test data. 
However, due to the increased complexity and the dynamic nature of the City Bus Transport Operations, it is very difficult for transport planner to make decisions by traditional methods of dealing with data without considering the utility of ICT. Further, due to the frequent changes in the original structuredness of the many decision problems in city-bus-transport planning, the decisionmaking process requires "what-if analyses" before taking any effective and efficient decision for any of the city-bus-transport decision problems. This decision making complexity made the decision maker to realize that the traditional computer based information systems could not address the decision-making contexts very well and this has resulted the next development of the IT, called " DSS - Decision Support System" (Turban and Aronson, [37]). DSS combine data and problem-solving methodologies to help decision makers in their work. DSS is originally running largely on mainframes and developed rapidly afterwards (Jun and Jun 2011 [17]). Akunal [1] defined DSS as "Decision Support Systems (DSS) are computer technology solutions that can be used to support complex decision making and problem solving”.

Today, for developing an effective DSS it is very much essential to understand the specific objective(s) of the DSS and the sequence of the steps that lead them to make decisions and the extent of the decision maker's influence exerted on them by the subjective attitudes and the specific context within which decisions are taken. Akumal [1] presented the different classifications of DSS examples in transport planning area for better understanding the relationships and differences in various models and scales. Furthermore, DSS are proposed for assisting transport planners in many areas such as DSS for urban traffic control system with an objective of minimizing traffic congestion level (Bielli, [7]; Hasan, [13]; Utama et al. [38]; Jaworski et al. [16]), GIS based DSS for analysis and evaluation of different transportation policies (Arampatzis et al. [3]); DSS for urban road transportation network planning (Jun, and Yikui, [18]); Maintenance problems in road transport (Roy, et al. [32]); DSS for urban mass transit service planning (Tan et al. [36]); and DSS for effective management and to support complex traffic and transportation decision problems of Delhi Bus Transportation System (Kurian and Jian, [22]). Though DSS has been developed for various decision problems related to URTS, to the best of our knowledge, there is no DSS for an integrated decision problem on LD-ABD to optimize the cost of bus operations.

Today, many enterprises have moved away from centralized, applications based on mainframe to distributed computing models that are based predominantly on service-oriented and Internet-oriented architectures for supporting decision makers (Jun and Jun, [17]). That is, the availability of today's pervasive networking, inexpensive storage, and high-performance computing has created the foundation for a broad range of new approaches capable of delivering on the promise of cloud computing for decision making (Russell et al., [33]). In addition, Jun and Jun [17] highlighted that existing applications and IT resources that are designed according to the principles of service 
orientation provide a solid foundation for the adoption or integration of Cloud-based frameworks for decision making. Akunal [1] indicated that a good user-friendly interfaces, particularly in web applications and smart devises (example: cloud computing) in transport decisions not only help individuals but also pave the way for the formation of smart societies.

Cloud computing services is the best solution for increase operational efficiency and productivity, at the same time lowering the costs and maximizing the investments (Shuleski et al. [35]). Armbrust et al. [5] defined the "cloud" as the environment where computing resources are hosted in and used from the distributed Internet environment. Russell et al. [33] explained that Cloud computing extends the notion of desktop computing to the scalability and virtualization of distributed processing servers on the Internet. According to the National Institute of Standards and Technology, Cloud Computing is defined as "Cloud computing is a model for enabling ubiquitous, convenient, on-demand network access to a shared pool of configurable computing resources (e.g., networks, servers, storage, applications, and services) that can be rapidly provisioned and released with minimal management effort or service provider interaction (Mell and Geance, [30]). Furthermore, Hsu et al. [14] defined Cloud computing as a distributed parallel computing technology based on the internet, in which computing resources are virtualized before they are provided to users so that they are able to access a variety of integrated hardware and software services via the internet. As cloud computing is capable of providing large amounts of high-capacity information storage and processing, it has led to a sharp increase in the amount of available information, as well as the need to provide timely value-added analysis services for large amounts of diverse data towards decision making. For understanding various key challenges, cloud computing evolution/milestones, cloud models and key cloud benefits, particularly with respect to Indian contact, readers can refer Agarwal and Dhingra [2].

Based on the continuous development on the IT paradigm and analytics, the transport planner has moved to utilize the cloud computing for many of their decision making. For example, there are studies related to Cloud computing based urban traffic control system (Jaworski, et al. [16]); Cloud based ITS (Ashokumar, et al. [6]); Intelligence transport management (Meneguette, [29]); Cloudbased intelligent transportation system (Hsu et al. [14]), etc. Though there are many key players in cloud computing arena (Martson et al. [25]) such as Amazon, Microsoft, Google, IBM, etc., there is no study utilizing the concept of cloud computing and DSS for the complex, dynamic and integrated decision problem on LD-ABD. This study attempts to fill this research gap.

\section{Cloud computing and a Cloud based DSS (C-DSS) for URTS}

Cloud computing represents a convergence of two major trends in information technology : (i) IT efficiency, whereby the power of modern computers is utilized more efficiently through highly scalable hardware and software resources and (ii) business agility, whereby IT can be used as a 
competitive tool through rapid deployment, parallel batch processing, use of compute-intensive business analytics and mobile interactive applications that respond in real time to user requirements (Marston et al., [25]). From the analysis of the literature, Cloud Computing is mainly described as an IT outsourcing model for on-demand, online delivery of scalable IT services on the basis of virtualization technology and pay-per-use pricing models (Leimeister et al. [23]). According to Weinhardt et al. [39] the Cloud Computing services are grouped into three categories: Software as a Service (SaaS), which refers to application services; Platform as a Service (PaaS), i.e. developer platforms; and Infrastructure as a Service (IaaS), which mainly denotes storage services and computing power services.

Due to availability of many Public IT cloud services, a cloud computing can provide the virtual infrastructure for utility computing integrating applications and it will enable businesses and users to access applications on demand anytime, anyplace and anywhere (Canellos, [9]). That is, cloud computing services are off-site from a customer's utilization point of view and the customer do not require any dedicated, application-specific or proprietary client-side hardware or software to support access. In addition, the advances in cloud computing and web of things (IoT) provides a promising chance to resolve the challenges caused by the increasing transportation problems (Ashokkumar et al. [6]). Particularly, using the cloud computing model, the organization that are involved in the passenger transport can significantly raise the quality of service they provide to the passengers with significant reduction of initial capital costs as this lets the organization's focus on the core activity itself, and minimize the resources necessary for work and control of IT infrastructure (Saric et al. ([34]).

Keeping the advantages of cloud computing and analytics, instead of proposing a specific DSS working on a stand-alone system in URTS, a cloud based DSS (C-DSS) is proposed for the decision problem considered in this study. Furthermore, according to the classification of cloud computing given by Weinhardt et al. [39], this study considers "Software as a Service (SaaS)" model for developing the proposed C-DSS. Accordingly, in this section, the complete description on the development of the Cloud based DSS (C-DSS), for Urban Road Transport System (called as C-DSSURTS), for obtaining efficient strategic decisions on (a) Allocation of Buses to Depots (ABD), and (b) Location of Depots (LD) and ABD (LD-ABD) problems using analytics based on efficient greedy heuristic algorithm and what-if analyses is discussed along with testing, verification and validation of the proposed C-DSS-URTS.

\subsection{Development of C-DSS-URTS}

C-DSS-URTS is developed using latest web technologies with a user-friendly web interface, which can be used in any browser. The proposed C-DSS-URTS is developed as a SaaS (Software as a 
Service) model in the cloud and it is currently deployed in Amazon Web Services, which enables the users to access it using from anywhere using any devices. The deployment architecture for this webbased C-DSS-URTS system is presented in Annexure 1. A schematic view of the proposed C-DSSURTS for optimizing ABD/LD-ABD problem is given in Figure 1. The proposed C-DSS-URTS consists of 5 interconnected modules, namely (i) Web Interface Module, (ii) Database Management Module, (iii) Model Management Module, and (iv) Report Generation Module, (v) Control Module. The development details of these 5 interconnected modules of the proposed C-DSS-URTS for optimizing $\mathrm{ABD} / \mathrm{LD}-\mathrm{ABD}$ problem, and their role in it are presented in the following sections:

\subsubsection{Web Interface Module (WIM)}

The overview of the Web Interface Module (WIM), developed for C-DSS-URTS, is shown in Figure 2. As shown in the Figure 2, the WIM supports the user to choose any one of option: Depot Management Interface, Terminus Management Interface, Bus Management Interface, Constraint Interface, ABD Interface, LD-ABD Interface, and What-if Analysis Interface. Detail of these interfaces, provided under WIM, is as follows:

Depot Management Interface: The Depot-Management option introduced in the WIM provides the required user interface to display the existing depots and its details. This provides options to "Create New", "Edit" and "Delete" regarding depot related data. While adding the depot details, the user has to provide the values of "depot code", "depot name", "current capacity", "additional capacity", "operating cost", "fixed cost" and "salvage cost". The "salvage cost" is an optional field which should be provided in case of the depot-closure. The "salvage cost" for the specific depot can be provided using the "Edit" option. A sample screen snapshot of "Depot Management Interface" of WIM and "Create New Depot" option in Depot-Management is given in Figure 3 and Figure 4 respectively.

Terminus Management Interface: The Terminus-Management option gives a user interface to "Add", "Delete" and "Edit" the terminus details of URTS. A sample screen snapshot for the interface: Terminus-Management is presented in Figure 5. While adding the terminus, the user needs to provide "terminus-code" and "terminus-name" and values for these are mandatory. The other important input is the "distance between the terminus and the depot". The "distance between terminus and depot" provides connectivity with all the depot-codes and a field to enter the distance. A sample screen snapshot for the options on "Create New Terminus" and "Distance between Terminus and Depot", provided under Terminus-Management option are given in Figure 6 and Figure 7 respectively. 


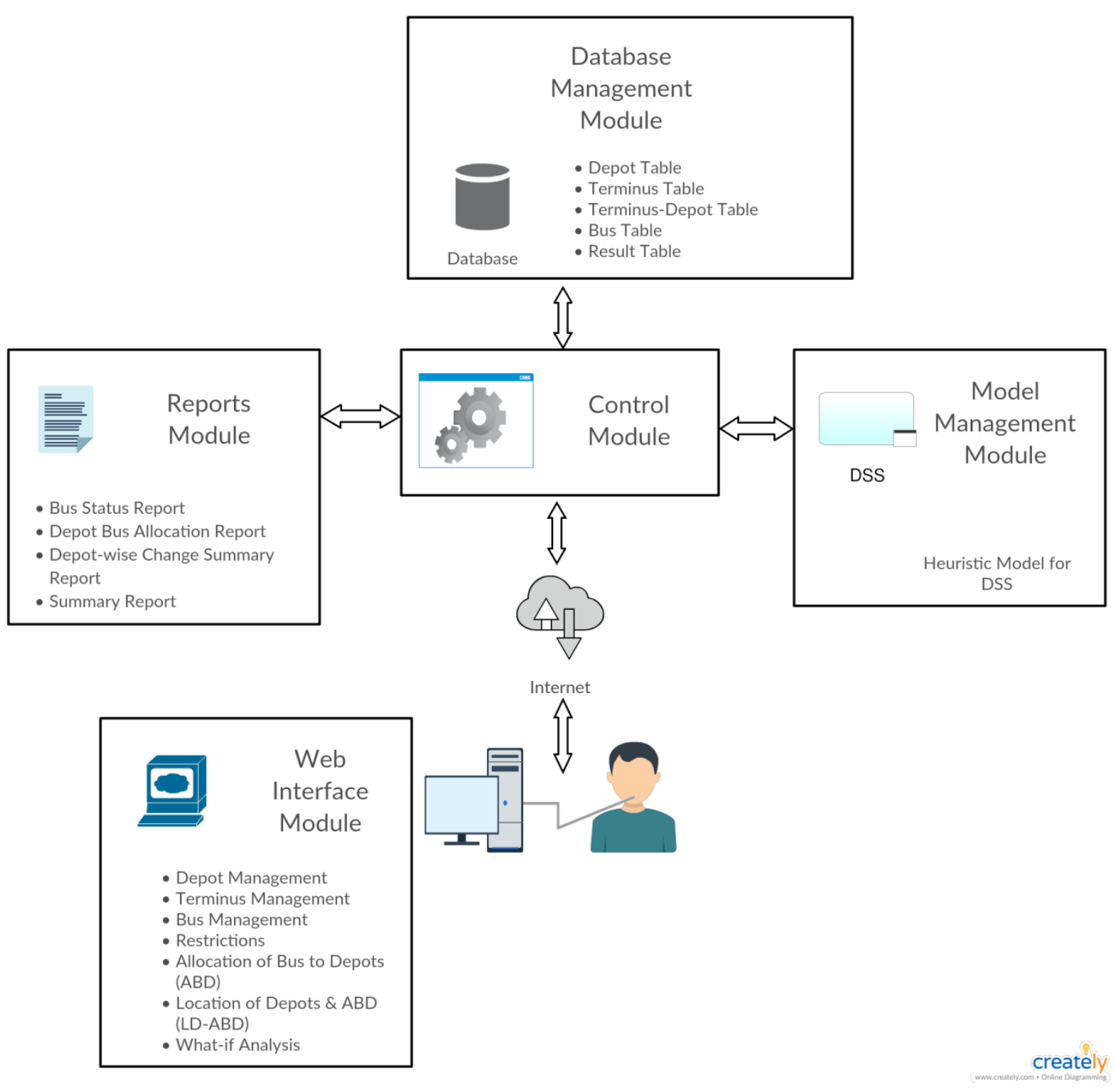

Figure 1: A Schematic View of the Proposed C-DSS-URTS 


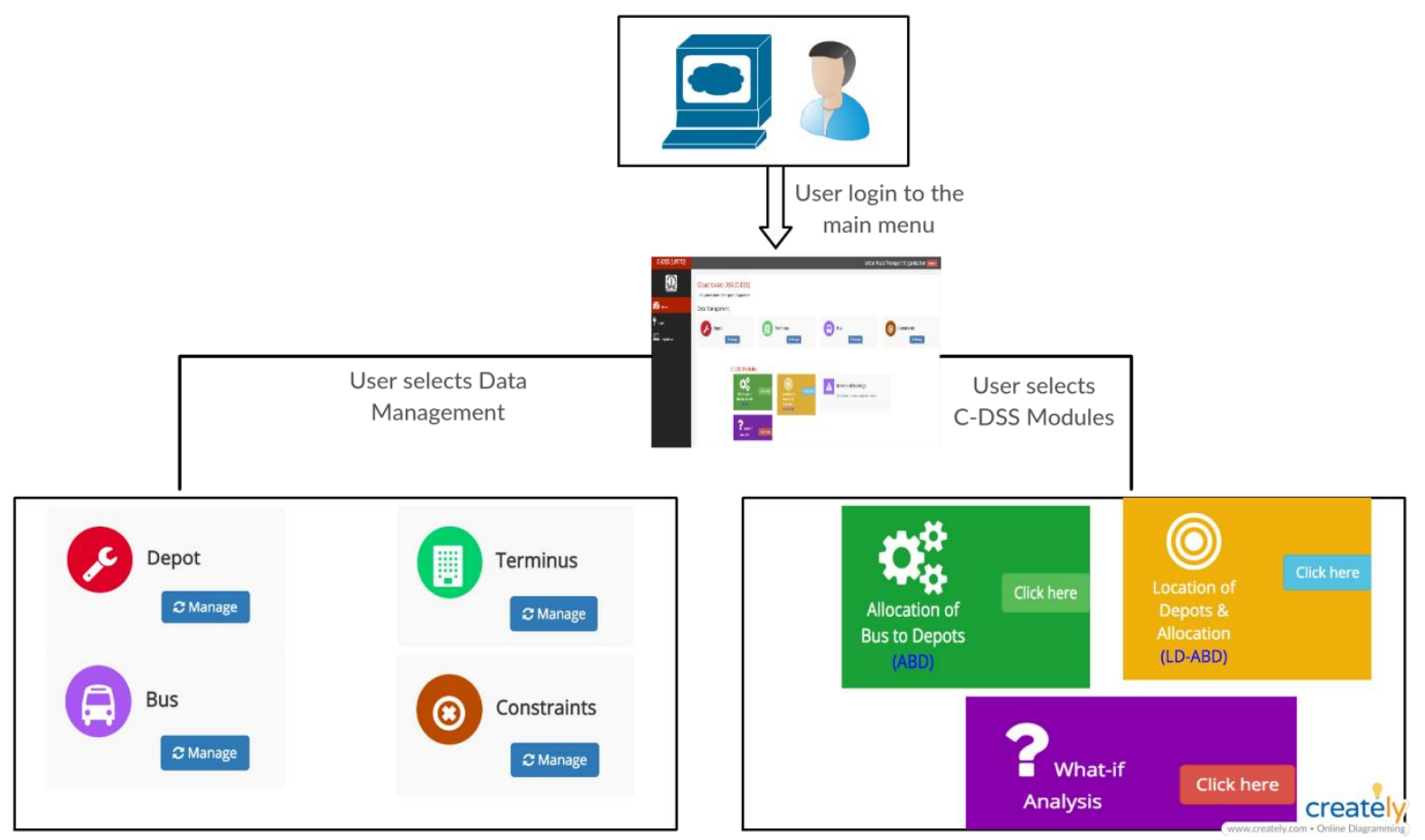

Figure 2: Web Interface Modules

\section{Depots}

\begin{tabular}{|c|c|c|c|c|c|c|c|c|c|c|}
\hline \multicolumn{2}{|c|}{ Create New } & Upload & & & & & & \multicolumn{2}{|l|}{ Search } & Search \\
\hline No & Code & Name & Curr. Capacity & Max. Capacity & Oper. Cost & Fixed Cost & Salvage Cost & Action & & \\
\hline 1 & D1 & Depot - D1 & 127 & 140 & 0 & 0 & 0 & Edit & Delete & \\
\hline 2 & D2 & Depot - D2 & 86 & 98 & 0 & 0 & 0 & Edit & Delete & \\
\hline 3 & D3 & Depot - D3 & 113 & 125 & 0 & 0 & 0 & Edit & Delete & \\
\hline 4 & D4 & Depot - D4 & 112 & 140 & 0 & 0 & 3423800 & Edit & Delete & \\
\hline 5 & D5 & Depot - D5 & 92 & 100 & 0 & 0 & 0 & Edit & Delete & \\
\hline
\end{tabular}

\begin{tabular}{|l|l|l|l|l|l|l|l|l|l|l|}
\hline 1 & 2 & 3 & 4 & 5 & 6 & 7 & $\ldots$ & 10 &, \\
\hline
\end{tabular}

Figure 3: A sample snapshot of Depot Management Interface 


\section{Add Depot}

Code :

\section{Code}

Name :

Name

Current Capacity :

Current_capacity

Additional Capacity :

Additional_capacity

Operating Cost :

Operating_cost

Fixed Cost :

Fixed_cost

Salvage Cost :

Salvage_cost

\section{Close Submit}

Figure 4 : A sample snapshot of "Create New Depot" option in Depot Management Interface 


\section{Terminus}

Create New Upload

\begin{tabular}{|l|l|}
\hline Search & Search \\
\hline
\end{tabular}

\begin{tabular}{|l|l|l|l|c|}
\hline No & Terminus Code & Terminus Name & Distance From/To Depot & Action \\
\hline 1 & MTQ & Terminus - MTQ & 1 Manage Distances & Edit \\
\hline 2 & ZVE & Telete \\
\hline 3 & ZGD & Terminus - ZGD & T Manage Distances & Edit Delete \\
\hline 4 & CZU & Terminus - CZU & T Manage Distances & Edit Delete \\
\hline 5 & HDM & Terminus - HDM & T Manage Distances & Edit Delete \\
\hline
\end{tabular}

\begin{tabular}{|l|l|l|l|l|l|l|l|l|l|}
\hline 1 & 2 & 3 & 4 & 5 & 6 & 7 & $\ldots$ & 24 &, \\
\hline
\end{tabular}

Figure 5: A sample snapshot of Terminus Management Interface

\section{Create Terminus}

Terminus Code :

Terminus Code

Terminus Name :

Terminus Name

Close

Submit

Figure 6: A sample snapshot of "Create New Terminus" option in Terminus Management Interface 


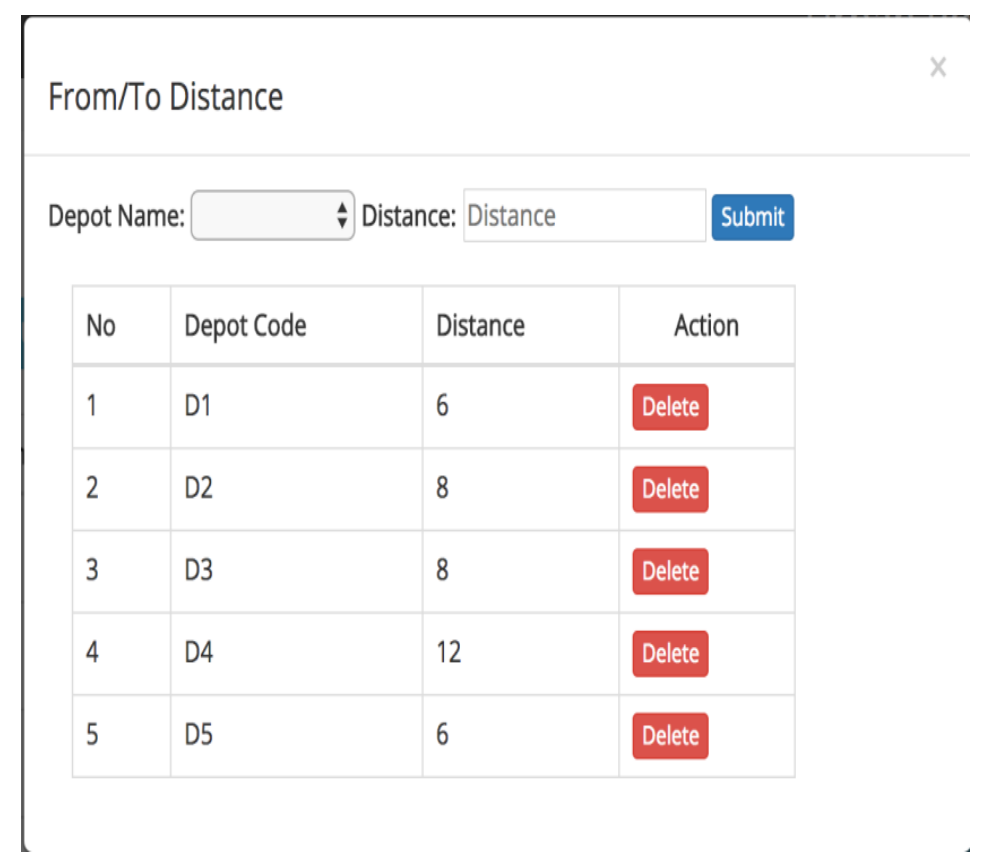

Figure 7: A sample snapshot of "Manage Distances" option in Terminus Management Interface 
Bus Management Interface: The Bus-Management interface provides options to "Add", "Edit", and "Delete" data related to buses. When the user adds details of new buses into the system, the values for parameters: bus-number, start-terminus, end-terminus, depot-code and fuel-cost-per-km needs to be provided. The start-terminus and end-terminus values need to be chosen from the list of terminus and the depot-code shown for each of these two data. A sample screen snapshot for this interface is provided in Figure 8. Also, a sample screen snapshot for the option: "Adding New Buses" in Bus Management Interface is presented in Figure 9.

Constraints Management Interface: This interface provides user to specify any special constraints on the allocation of a bus to the available depots. For example, the management decides that a particular bus should not be allocated to a set of available depots due to bus-type (example: AC Bus, Non-AC Bus, etc.). If this constraint is added to the database, then the solution methodology, provided in the Model Management Module (MMM), will make sure that the bus is not allocated to those set of available depots. While adding a constraint, the user needs to select the bus-number and the depot-code where the bus should not be allocated to the depot by the proposed C-DSS-URTS. The user also can provide "remarks" for this constraint as an additional reference. A sample screen snapshot for providing the details on this specific constraint is given in Figure 10.

Allocation of Buses to Depots (ABD) Interface: The ABD interface provides the summary of data and an option to execute the solution methodology, provided in the Model Management Module (MMM) of C-DSS-URTS, for obtaining efficient solution/decision for ABD problem of URTS. A sample screen snapshot for the ABD interface is given in Figure 11. When the option "ABD" is invoked, there is an option "Optimize" appears. The option "Optimize" displays the basic data such as the number of depots, number of terminus, and number of buses. If we click "Optimize", then the proposed C-DSS-URTS runs for efficiently allocating the given number of buses to given number of depots and stored the outputs for displaying using "Report Generation Module (RGM)" of the proposed C-DSS-URTS. If the efficient solution/decision is already obtained, the stored results can be displayed in multiple reports format using RGM of the proposed C-DSS-URTS. It also provides to re-run the algorithm if any data is modified.

Location of Depots and ABD (LD-ABD) Interface: The LD-ABD interface provides the user to finalize the data for "Possible depots to be closed", "Exact number of depots to be closed", "Probable number of depots to be opened", "Exact number of depots to be opened", "Terminus to be added", and "Buses to be added" for obtaining optimal/efficient solution for LD-ABD problem of URTS. That is, the LD-ABD interface provides the existing data on ABD and LD-ABD data along with option to add other information as shown in Figure 12. 
Existing Depot \& Bus Allocation

Create New Upload
\begin{tabular}{|l|l|l|l|l|l|l|l|}
\hline No & Depot Code & Route No. & Start Terminus & End Terminus & Fuel Cost & Action \\
\hline 1 & D1 & R0 & MAO & AED & 12 & Edit & Delete \\
\hline 2 & D1 & R1 & KXL & CZU & 9 & Edit Delete \\
\hline 3 & D1 & R2 & CZL & IYE & 10 & Edit Delete \\
\hline 4 & D1 & R3 & STO & NCK & 9 & Edit Delete \\
\hline 5 & D1 & R4 & KPR & WFQ & 12 & Edit Delete \\
\hline
\end{tabular}

\begin{tabular}{|l|l|l|l|l|l|l|l|l|l|l|}
\hline & 1 & 2 & 3 & 4 & 5 & 6 & 7 & $\ldots$ & 1046 &, \\
\hline
\end{tabular}

Figure 8: A sample snapshot of Bus Management Interface

\section{Allocate Bus to Depot}

Route No:

Route No

Depot Name :

$\Delta$

Start Terminus :

$\Delta$

End Terminus :

$\Delta$

Fuel Cost per km:

Fuel Cost per km

Close

Submit

Figure 9: A sample snapshot of Create new bus in Bus Management Interface 


\title{
Add Route Constraints
}

\author{
Route Number : $\mathrm{R} 2 \quad \mathbf{\nabla}$
}

Depot Code : Depot-D3

Remarks :

Remarks

\section{Close Submit}

Figure 10 : A sample snapshot of Constraints Management Interface

\section{Optimize}

\begin{tabular}{|l|l|}
\hline Available data \\
\begin{tabular}{|l|l|}
\hline Category & Numbers \\
\hline Depots & 50 \\
\hline Terminus & 120 \\
\hline Bus & 5229 \\
\hline
\end{tabular} \\
Algorithm already executed and results are available. Click below to view the results: \\
ABD Form 4 Depot-wise Change Summary Summary Report View Data \\
Re-run the algorithm if any data is modified by clicking below: \\
Execute Again!
\end{tabular}

Figure 11: A sample snapshot of ABD Management interface 
Location of Depots and Allocation of Depot (LD-ABD)

\begin{tabular}{|c|c|c|c|}
\hline \multicolumn{4}{|c|}{ Existing Data: } \\
\hline \#of Depots & Depot Capacity & Terminus & Buses \\
\hline 50 & 5229 & 120 & 5229 \\
\hline
\end{tabular}

LD-ABD Data:

\begin{tabular}{|l|l|l|l|l|l|}
\hline \multicolumn{2}{|l|}{ Depots } & \multicolumn{2}{l|}{} \\
\hline Possible to close & Exact \# to be closed & Possible to open & Exact \# to be opened & Terminus & Buses \\
\hline 2 (D17,D42) & 1 & $3($ LD0, LD1, LD2) & 2 & 0 & 0 \\
\hline
\end{tabular}

\begin{tabular}{lll} 
Depot - Closing Depot - New & Terminus - Add Buses - Add \\
\hline
\end{tabular}

Figure12: A sample snapshot of LD-ABD Management Interface 
After providing all the input information in LD-ABD interface, the option: "LD-ABD" can be invoked. After invoking "LD-ABD" option, there is an option "Optimize" appears. When we click the option "Optimize", then the C-DSS-URTS will run for each possible combinations of Closing exact number of depots from the feasible set of closing existing depots along with opening exact number of new depots from the feasible set of opening new depots, and displays the results for each combinations to choose the user's choice on the combination of closing and opening depots with a criterion on total cost obtained due to dead kilometer cost, fixed cost and salvage value.

What-if Analysis Interface: The user can perform "What-if" Analysis for various scenarios by carrying out the operations: Modifying depot (specifying what-if capacity changes) capacity, Adding terminus, Adding buses, and Changing the existing terminus for a bus. For each of "what-if" analysis scenarios, the user can run the proposed C-DSS-URTS for obtaining optimal/efficient solution for $\mathrm{ABD}$ or $\mathrm{LD}-\mathrm{ABD}$ problem for the change in scenario. A screen snapshot for the "What-if Analysis interface" is provided in Figure 13.

\subsubsection{Database Management Module (DMM)}

The Database Management Module (DMM) maintains all databases required for solving the decision problems: ABD or LD-ABD in optimizing the cost of operation of City Buses through C-DSS-URTS. The databases required for the C-DSS-URTS are (a) Depot_Table, (b) Terminus_Table, (c) Terminus_Depot_Table, (d) Bus_Table, and (e) Result_Table. The details on each of these databases are as follows:

Depot_Table: The Depot_Table captures, for each depot, 12 attributes' values in 12 columns related to Serial number, Depot-Code, Depot-Name, Division, Current-Capacity, Maximum-Capacity, Whatif Capacity, Operating-Cost, Salvage-Cost, Fixed-Cost, Organization-code, and Purpose respectively. The database structure of the "Depot_Table" defined in C-DSS-URTS is shown in Exhibit 1 of Annexure 2. The details on each of the 12 attributes of the Depot_Table are explained as follows:

Column 1: Serial-Number: This column contains serial number of the record, which is automatically generated by the database module of C-DSS-URTS. This will be the "primary key" for each record and this will have a unique value in all the depots. This value should not be modified, and it is used only by the database. This is not displayed in any reports.

Column 2: Depot-Code: For each depot, a code will be assigned. There is no specific naming convention followed in C-DSS-URTS. For all the testing-scenarios of the proposed C-DSS-URTS, the code was defined as " $\mathrm{D}$ " followed by serial number. For example, the first Depot-Code was assigned as "D1", second depot as "D2" and so on. In some cases, the short form of the DepotName can be considered as Depot-Code. For example, if the Depot-Name is "Gandhi Nagar", the Depot-Code can be "GND", which indicates "Gandhi Nagar Depot". The Depot-Code is used in the reports to indicate the location of the depot. The maximum number of characters (in the form of alphabets and numbers) for representing the Depot-code is 20. 
What if analysis

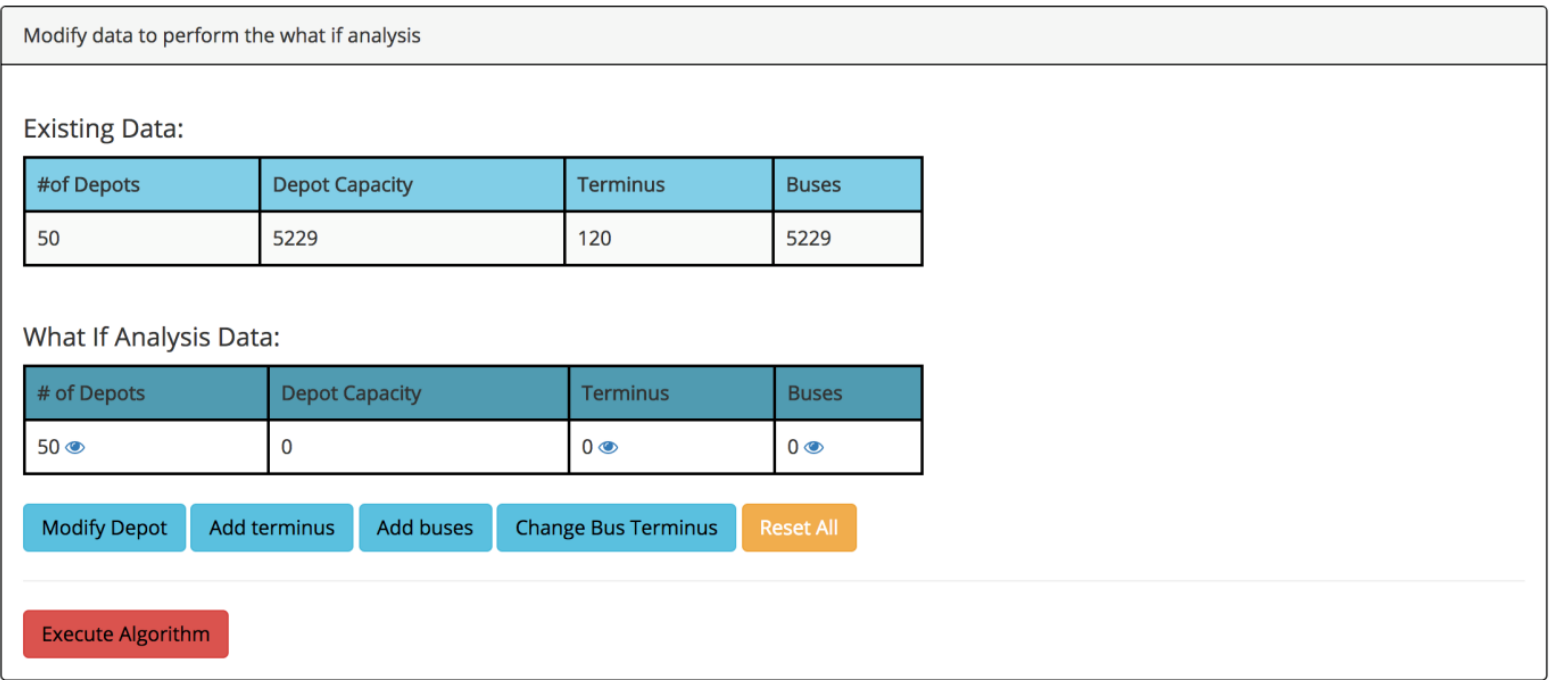

Figure 13 : A sample snapshot of what-if analysis management interface 
Column 3: Depot-Name: The Depot-Name is stored in $3^{\text {rd }}$ column of the Depot_Table. In general the Depot-Name will be the name of the location, where the depot is located. For example, if the depot is located in "Shanthi Nagar", then the Depot-Name can be "Shanthi Nagar". In some cases, if more than one depot is located in the same location, a roman numerical can be appended. (Eg."Shanthi Nagar I", "Shanthi Nagar II", etc.). The C-DSS-URTS allows a maximum of 40 characters (with special characters, numbers and alphabets) to represent Depot-Name. The DepotName will be displayed in all the relevant reports, to be generated by C-DSS-URTS.

Column 4: Division:_The $4^{\text {th }}$ column of the Depot_Table is used to store the value of the attribute: Division, if the depots are grouped into multiple divisions. For example, to represent a depot belongs to "south division" or "north division", etc., of the city, the attribute: Division will be defined in $4^{\text {th }}$ column of Depot_Table. This is stored only for the information purpose.

Column 5: Current-Capacity: The number of buses currently allocated in each of the depot will be captured using the attribute: "Current-Capacity" of Depot_Table. The value of Current-Capacity should not be zero and it can store only integer numbers.

Column 6: Maximum-Capacity: The number of buses actually possible to allocate in each of the depots (called as Maximum-capacity), which is either equal or greater than the number of buses currently allocated (called as Current-capcity), will be stored in the attribute: "MaximumCapacity" of the respective depot in Depot_Table. During the "What-if" analysis of C-DSS-URTS, the user can increase the number of buses from Current-Capacity to Maximum-Capacity of a specific depot in order to learn how the optimal decisions related to ABD or LD-ABD problems changes. However, increasing the number of buses to the specific depot should not exceed the valued stored in $6^{\text {th }}$ Column of Depot_Table (that is, the value of "Maximum-Capacity").

Column 7: What-if-Capacity: The value of "increased capacity" (which is up to equal to Maximum-Capacity) from Current-Capacity, considered for What-if analysis, is stored in the attribute: What-if-Capacity of Depot_Table.

Column 8: Operating-Cost: The Operating-Cost of the depot is stored in this column. The accepted value is only integer. Currently this value is not used in C-DSS-URTS for obtaining optimal/efficient solution while solving the decision problems: ABD or LD-ABD.

Column 9: Salvage-Cost: The Salvage-Cost occurs to the transport organization when an existing depot is planned to close. This value is mandatory for "LD-ABD" problem when the existing depot is possible to close while running C-DSS-URTS. The accepted value is integer.

Column 10: Fixed-Cost: The value of the attribute: Fixed-cost is required for each of the new depots, which are planned to open while running C-DSS-URTS for LD-ABD problem. For the existing depots, this value should be zero. This cost indicates the overall cost in establishing and opening a new depot. This value is mandatory for "LD-ABD" problem and the accepted value is integer.

Column 11: Organization-Code ${ }^{1}$ : The Organization-Code represents the specific URTS, who uses the C-DSS-URTS. As the proposed C-DSS-URTS can be used by multiple URTS, the value stored in "Organization-Code" will be used along with all the databases (that is, all input tables) and all the reports (that is, all output tables) to uniquely identifying the databases and the reports related to specific URTS. These values are stored automatically by the C-DSS-URTS based on the login. This will not be displayed in any reports.

\footnotetext{
${ }^{1}$ Input value for 'Organization Code' is captured in all the databases (that is, all input Tables), required for C-DSS-URTS. So this attribute is not detailed again in each of the other databases, mainly to avoid the redundancy.
} 
Column 12: Purpose $^{2}$ : The value of this column indicates the purpose of depot data such as creating additional depots for "What-if" analysis or running "LD ABD" problem. Based on that, the value "Purpose" will have a unique code to identify the right records from the databases. This data is used only by the system and will not be displayed in any reports.

Out of 12 values of the 12 attributes in Depot_table, the critical attributes used by the optimal solution are Current-Capacity (This is mandatory for all the depots: both existing and new depots), MaximumCapacity (value should be greater than the current capacity and indicates that this capacity can be expanded in the existing depot), and What-if-Capacity (used only to find the optimal solution in case of an increased capacity).

Terminus_Table: The Terminus_Table stores 5 values of the parameters: Terminus-Id, TerminusCode, Terminus-Name, Organisation-Code, and Purpose in 5 columns. The database structure defined for the "Terminus_Table" is shown in Exhibit 2 of Annexure 2.

Terminus_Depot_Table: The Terminus_Depot_Table stores 6 values of the parameters related to Record-Id, Terminus-Code, Depot-Code, Distance, Organization-Code, and Purpose in 6 columns. The main objective of creating this table is to store the distance between each terminus to each of the depots. For example, if there is a terminus code "ABC" and 3 depots namely "D1", "D2" and "D3", then this table stores 3 records as distance between the terminus and each of the depot. The database structure defined for capturing the "Terminus_Depot_Table" is presented in Exhibit 3 of Annexure 2.

Bus_Table: The Bus_Table stores values of 8 parameters: Record-Id, Bus-Number (Route-Number), Depot-Code, Starting-Terminus, Ending-Terminus, Fuel-Cost-per-km, Organisation-Code, and Purpose and these are required for every bus. The database structure defined to capture "Bus_Table" is given in Exhibit 4 of Annexure 2.

Route_Depot_Constraints_Table: This table stores the information on special constraints (such as a bus should not be allocated to any one depot or specific set of depos), if any, between the depot and bus. If an entry made in this Route_Depot_Constraints_Table with a specific bus and depot code, then the C-DSS-URTS will make sure that this specific bus is not getting allocated to that specific depot as specified in the table. This Route_Depot_Constraints_Table stores 6 values of the parameters: Record-Id, Bus_Number, Depot-Code, Remarks, Organisation-Code, and Purpose. The database structure defined for Route_Depot_Constraints_Table is shown in Exhibit 5 of Annexure 2.

\footnotetext{
${ }^{2}$ Input value for 'Purpose' is captured in all the databases (that is, all input Tables), required for C-DSS-URTS. So, this attribute is not detailed again in each of the other databases, mainly to avoid the redundancy.
} 
Result_Table: The Result_Table stores the values of 5 parameters: Record-id, Depot-Code, BusNumber, Organization-Code, and Purpose related to the optimal/efficient solution for the problem $\mathrm{ABD}$ or LD-ABD. Once the C-DSS-URTS generates the results, it is stored in this table. Using the optimal/efficient solution stored in this table, various reports can be generated. The database structure defined for capturing the values of the 5 parameters related to Result_Table is presented in Exhibit 6.

LD-ABD Table: This LD-ABD_Table stores the values of 8 parameters: Record-Id, PossibleClosing-Depot-Codes, Possible-Number-of-Depots-to-be-Closed, Exact-Number-of-Existing-Depotsto-be-Closed, Possible-Number-of-New-Depots-to-be-Opened, Exact-Number-of-New-Depots-to-beOpened, Number-of-New-Buses-to-be-added, and Organisation-Code and these are required for executing the C-DSS-URTS for optimizing optimal/efficient solution for the LD -ABD problem. The database structure defined for the LD-ABD_Table is given in Exhibit 7 of Annexure 2.

\subsubsection{Model Management Module (MMM)}

The MMM is the most important module in C-DSS-URTS. Similar to DMM, the MMM module has model base and model dictionary. In general, the model base has a set of models for predicting, prescribing, and describing related to the problems considered in the specific DSS. From the analysis of the literature it is learnt that both $\mathrm{ABD}$ and $\mathrm{LD}-\mathrm{ABD}$ problems, considered in this study for developing DSS, becomes computationally intractable when the actual real-life problem size and constraints are considered (Mathirajan, [26]) due to the violation Unimodular property (Winston [41]) of the mathematical model proposed for $\mathrm{ABD}$ and $\mathrm{LD}-\mathrm{ABD}$ problems and/or due to the large number of binary variables involved in the formulation. With this many have proposed various heuristic algorithms for solving ABD problems (Mathirajan et al. [27], Kontu et al. [21]) and LD-ABD problems (Willoughby and Uyeno, [40], Mathirajan et al. [28]). With this backdrop, for the proposed C-DSS-URTS, the model base has a simple efficient heuristic algorithm to address ABD problem as well as LD-ABD problem and appropriate interface to carry out what-if analysis. The heuristic algorithm incorporated in the model base of the MMM is an extension to the heuristic algorithm proposed in Mathirajan et al. [28].

The heuristic algorithm proposed in Mathrajan et al. [28] to address the LD-ABD problem follows a two-phase approach. In the first phase of the algorithm a best combination of expected number of new depots to be opened and old depots to be closed is determined, by completely enumerating the possible combination of a set of expected number of new depots to be opened (from the given possible number of new depots for opening) along with a set of expected number of existing depots to be closed (from the possible number of existing depots for closing) and comparing the sum of fixed cost and salvage cost (associated with opening new depots and closing existing depots respectively) 
for each combination. After obtaining the best combination of a set of new depots by opening and a set of existing depots by closing, a new set of total optimal combinations of depots ( $=$ Total number of given existing depots - exact number of existing depots to be closed + exact number of new depots to be opened) will be arrived. Considering the total optimal combination of depots obtained from the first phase of the algorithm, the given number of existing buses plus the proposed number of new buses are optimally/efficiently will be allocated in the second phase of the algorithm using the popular VAM method to get the optimal/efficient solution for LD-ABD problem and to minimize the total dead-kilometer cost.

The two-phase approach followed in the heuristic algorithm proposed in Mathirajan et al. [28] for solving LD-ABD problem, all the three cost: total fixed cost associated with opening new depots, total salvage values associated with closing existing depots, and total dead-kilometer cost associated with ABD problem, are not considered simultaneously while optimizing the cost of operations. This might lead to inferior solution when we compare with a method which could consider simultaneously all the three cost. With this backdrop, the heuristic algorithm proposed in Mathirajan et al. [28] is extended to address all the three costs simultaneously and the step-by-step detail of this extended heuristic algorithm is presented in Annexure 3. In addition to the heuristic algorithm incorporated in the model base, an appropriate system routine is provided in the model-base for all the possible "whatif analyses' proposed in the C-DSS-URTS.

As per the functioning part of the MMM, the MMM invoke the required input for ABD problem or LD-ABD problem suitably depending on the decision maker's choice on optimally solving ABD problem or LD-ABD problem respectively. Particularly the heuristic algorithm incorporated in the model base requires the following basic input data to obtain optimal/efficient solution for either ABD or LD-ABD problem of URTS:

- List of depots

- List of terminuses and the distance between each terminus to each depot

- List of buses and its existing allocation to the depots

- Dead kilometer cost for each bus

Particularly, these input data is invoked in C-DSS-URTS for obtaining optimal/efficient solution for the following scenarios:

- Allocation of Bus to Depots (ABD): In the case of ABD problem, based on the data provided, using simple greedy heuristic algorithm implemented in the MMM, the efficient allocation of buses to the depots to minimize the total dead kilometer cost will be obtained. 
- Location of Depots and Allocation of Buses to Depots (LD-ABD): There are scenarios where the user wanted to close few depots by specifying the salvage cost and open new depots by providing fixed cost. In this context, the user also wanted to add new buses and terminuses. After adding the relevant data for these, the user wanted to make a decision on what is the right combination of closing (existing depots) and opening (new depots) the depots. To learn this, the C-DSS-URTS will run the ABD algorithm for each of the combinations made considering the constraints on number of depots to be closed and number of new depots to be opened. In the end, the C-DSS-URTS shows the optimal/efficient total cost for each combinations considered based on the given data for $\mathrm{LD}-\mathrm{ABD}$ problem and allows the user to choose his/her combination in terms of the choice of the depots considered for closing and opening.

- What if Analysis : There are various scenarios (one at a time): modifying the existing depot capacity feasibly, and/or adding more buses to the depots feasibly, and/or adding more terminuses by providing all the required additional dead-kilometer between each of the new terminuses and each of the depots considered in the system are defined in What-if analysis routing of the C-DSS-UTRO. That is, the web interface module (WIM) provides user interface to modify the depot capacity, add more buses, add more terminus through 'What if analysis option. All the scenarios defined under What-if analysis, the system uses the heuristic algorithm incorporated in the model-base of the MMM, appropriately. Furthermore, for each of the scenarios, defined in the C-DSS-URTS for What-if analysis, the C-DSS-URTS is executed to view the impact of the results due to the modified data on buses / depot capacity / terminuses. That is, these What-if analysis gives the user a learning features of what happens to the result for a specific scenario.

\subsubsection{Report Generation Module (RGM)}

The C-DSS-URTS generates the optimal/efficient solution and the same is stored into Result_Table. The report generation module (RGM) generates the reports based on the data stored in the DMM and the solution stored in Result_Table for the decision problem: ABD or LD-ABD. The generated reports can be presented in screen and can be stored in MS-Excel also. That is, the report generation module retrieves the data from the database tables as well as result table and produces the following reports:

- Bus_Status_Report: For each bus, the details about (a) the Starting-Terminus, EndingTerminus, existing allocation in terms of the depot, the distance and the cost due to the existing system (and these are extracted from appropriate database tables); and (b) the 
optimal/efficient solution in terms of the choice of depot for allocation of bus, the distance and the cost due to the allocation of a bus to a depot due to C-DSS-URTS ( and these are extracted from result table) are generated and reported as Bus_Status-Report. A sample report is presented in Exhibit 8 of Annexure 2.

- Bus_Depot_Allocation_Report: This report displays Bus-Number (or Route-Number), depot allocated by C-DSS-URTS, terminus details, fuel cost per km, dead kilometer cost, etc. A sample report is presented in Exhibit 9 of Annexure 2.

- Depot_wise_Change_Summary_Report: This report provides the change summary for each depot by providing details on 'list of buses moved from existing depot to the depot decided by C-DSS-URTS' and 'the list of buses allocated to depot by C-DSS-URTS from other depots'. A sample report is presented in Exhibit 10 of Annexure 2.

- Summary_Report: This report provides a summary at the depot level. For each depot, how many buses are allocated and its total dead kilometer as well as total dead kilometer cost. These details are presented corresponding to both existing allocation and the optimal/efficient allocation obtained from C-DSS-URTS. Finally, the cost savings also computed and presented. A sample report is presented in Exhibit 11 of Annexure 2.

\subsubsection{Control Module (CM)}

The control module $(\mathrm{CM})$ receives the request from the web interface and redirects the control to the respective modules of C-DSS-URTS. The control interface in general follows the below steps for every request:

Step 1: Gets the request from the user interface.

Step 2: Checks the type of request.

Step 3: If the request is to add information related to depots, buses or terminus, it will invoke the respective operation in the Database Management Module (DMM).

Step 4: If the request is viewing the information, it requests the DMM to retrieve the data from the database. Then the control redirects to the user interface module with the required data/information and the user can view the data/information.

Step 5: If the request is to delete the information, it requests the DMM to delete the respective record in the database. An appropriate message is also displayed in the UI through web user interface module.

Step 6: If user requests to execute the algorithm, the control redirects to the Model Management Module (MMM) which executes the algorithm for solving the respective ABD or LD-ABD problem. 
Step 7: If the report options are selected in the user interface, the Control Module (CM) generates the reports using the Reports Module (RM) and allows the user to download it in excel format.

\subsection{Testing and Verification of the Implementation of C-DSS-URTS:}

Testing: To assure the quality and reliability of any new software it is necessary to test it in different phases using various standard testing methods. The testing methods used for testing the proposed CDSS-URTS are Module Testing, Functional Testing, User Interface Testing and Systems Testing. The details of these testing are as follows:

- Module Testing - Each module is tested independently to check whether the interfaces to the methods are working fine.

- Functional Testing - Each function written in the modules are tested independently and the functionality is tested using the simulated data.

- User Interface Testing - The web interface components are tested to make sure that the appropriate information is retrieved from the backend and also information is stored into the backend.

- System Testing - This testing makes sure that all the different modules along with the user interface works fine.

As part of the implementation, several test cases had been identified and testing is done against those test cases.

Verification: The appropriateness of the formulation of three decision making scenarios on $A B D$, LD-ABD, and What-if Analysis proposed in C-DSS-URTS, several small-scale data (sample small scale data is presented in Annexure 3) are considered. These small-scale problems are solved using the C-DSS-URTS and verified the solution obtained from the C-DSS-URTS with the solution obtained by solving these small-scale problems manually.

\section{Validation of the Proposed C-DSS-URTS}

For validating the proposed C-DSS-URTS, a real-life case study data is most preferred. Due to confidential problem of the real-life case study data of BMTC and the difficulty in obtaining multiple real-life data related to $\mathrm{ABD}$ and $\mathrm{LD}-\mathrm{ABD}$ problems of various URTS, this study considered 25 large scale data, generated randomly based on the observation from BMTC, Bangalore. The macro characteristics of the ABD and LD-ABD problem of these 25 large scale data are presented in Table 2 (column 2 to 3 ) and Table 3 (column 2 to 9) respectively. Each of these 25 large scale data is solved considering ABD problem using the proposed C-DSS-URTS and obtained the total dead-kilometer as well as the total dead-kilometer cost. These results are presented in Table 2. 
For performance evaluation of the proposed C-DSS-URTS for ABD problem, the solution obtained from the existing practice and the optimal solution obtained from the existing mathematical model (Raghavendra and Mathirajan, [31]) is compared. Accordingly, for each of the 25 problem instances, both total dead-kilometer as well as total dead-kilometer costs are obtained with respect to existing practice and the exact procedure. These details are presented in Table 2. From the performance analysis on the results presented in Table 2, it is observed that the proposed C-DSS-URTS is providing efficient solution with a loss of optimality between $1 \%$ and $4 \%$ for ABD problem.

Similarly, each of the 25 large scale data related to LD-ABD problem is solved using the proposed CDSS-URTS and obtained the total cost (which is the sum of total fixed cost associated with opening a few new depots, total salvage value associated with closing a few existing depots, and total deadkilometer cost associated with allocating the total number of buses to the available number of depots in the problem) and presented in Table 3. For evaluating the performance of the proposed C-DSSURTS with respect to LD-ABD problem, the mathematical model presented in Mathirajan et al. [28] is considered as bench mark procedure. Accordingly, for each of the 25 problem instances are solved using the mathematical model presented in Mathirajan et al. [28] and the total optimal cost obtained is presented in Table 3. From the performance analysis on the results presented in Table 3, it is observed that the proposed C-DSS-URTS is providing efficient solution with a loss of optimality between $0 \%$ and $3 \%$ for $\mathrm{LD}-\mathrm{ABD}$ problem.

\section{Discussion}

The most outstanding features of the proposed C-DSS-URTS for ABD or LD-ABD are its quasi-realtime decision making support, intuitive and wizard-style interfaces and excellent scalability. The appropriateness in implementing the proposed C-DSS-URTS is carried out by conducing suitable testing and verification. Finally, the external validation of the proposed C-DSS-URTS for ABD or LD-ABD problem is carried out on large scale 25 pseudo real-life data of URTS and showed that CDSS-URTS for ABD or LD-ABD problem can meet the goals of achieving intuitive and concise interfaces and supporting real-time or quasi real-time decision making. In addition, the required modern information and communications technology tools and analytics as well as "What-if analyses', which are based on simple greedy heuristic algorithm, are incorporated in the proposed CDSS-URTS to decide the near optimal/efficient location of depots (from the options given for both opening new depots and closing a few existing depots) and allocation of buses to depots is extremely useful for optimizing the cost of bus operations in URTS. 
Table 2: The Performance of the C-DSS-URTS for ABD problem in Comparison with Existing System and Proposed (0-1) ILP Model

\begin{tabular}{|c|c|c|c|c|c|c|c|c|c|c|c|c|}
\hline \multirow{3}{*}{ Run } & \multicolumn{2}{|c|}{$\begin{array}{c}\text { URTS with \# } \\
\text { Depots and Buses }\end{array}$} & \multicolumn{2}{|c|}{$\begin{array}{l}\text { Existing Systems' } \\
\text { Performance w.r.t. }\end{array}$} & \multicolumn{2}{|c|}{$\begin{array}{l}\text { C-DSS-URTS's } \\
\text { Performance w.r.t. }\end{array}$} & \multicolumn{2}{|c|}{$\begin{array}{l}\text { 0-1 ILP's Performance } \\
\text { w.r.t. }\end{array}$} & \multicolumn{4}{|c|}{$\begin{array}{l}\text { Relative performance of C-DSS-URTS, in terms of \% age, } \\
\text { w.r.t. }\end{array}$} \\
\hline & \multirow[t]{2}{*}{$\begin{array}{c}\text { \# of } \\
\text { Depots }\end{array}$} & \multirow{2}{*}{$\begin{array}{l}\text { Total \# of } \\
\text { Buses }\end{array}$} & \multirow{2}{*}{$\begin{array}{l}\text { Total Dead } \\
\text { Kilometer }\end{array}$} & \multirow{2}{*}{$\begin{array}{l}\text { Total Dead } \\
\text { Kilometer } \\
\text { Cost }\end{array}$} & \multirow{2}{*}{$\begin{array}{l}\text { Total Dead } \\
\text { Kilometer }\end{array}$} & \multirow{2}{*}{$\begin{array}{l}\text { Total Dead } \\
\text { Kilometer } \\
\text { Cost }\end{array}$} & \multirow{2}{*}{$\begin{array}{l}\text { Total Dead } \\
\text { Kilometer }\end{array}$} & \multirow{2}{*}{$\begin{array}{l}\text { Total Dead } \\
\text { Kilometer } \\
\text { Cost }\end{array}$} & \begin{tabular}{|c|} 
Improvement over \\
Existing System
\end{tabular} & $\begin{array}{l}\text { Loss w.r.t. } \\
\text { known } \\
\text { solution }\end{array}$ & $\begin{array}{c}\text { Improvement over } \\
\text { Optimal Solution }\end{array}$ & $\begin{array}{c}\text { Loss of } \\
\text { Optimality }\end{array}$ \\
\hline & & & & & & & & & \multicolumn{2}{|c|}{ in Total Dead Kilometer } & \multicolumn{2}{|c|}{ in Total Dead Kilometer Cost } \\
\hline 1 & 10 & 1335 & 27486 & 303899 & 11871 & 130254 & 11729 & 129007 & 56.8 & 1.2 & 57.1 & 1.0 \\
\hline 2 & 10 & 1058 & 13591 & 142599 & 6047 & 63467 & 5986 & 62866 & 55.5 & 1.0 & 55.5 & 1.0 \\
\hline 3 & 10 & 1255 & 16646 & 175225 & 7069 & 74142 & 6981 & 73297 & 57.5 & 1.3 & 57.7 & 1.2 \\
\hline 4 & 10 & 1463 & 18074 & 190343 & 8647 & 90835 & 8602 & 90353 & 52.2 & 0.5 & $\begin{array}{l}52.3 \\
\end{array}$ & 0.5 \\
\hline 5 & 10 & 1501 & 21335 & 224253 & 8891 & 93019 & 8707 & 91211 & 58.3 & 2.1 & 58.5 & 2.0 \\
\hline Average & 10 & 1322 & 19426 & 207264 & 8505 & 90343 & 8401 & 89347 & 56.1 & 1.2 & 56.2 & 1.1 \\
\hline \begin{tabular}{l|l}
1 \\
\end{tabular} & 20 & 2384 & 49241 & 544908 & 17581 & 193690 & 17212 & 189858 & 64.3 & 2.1 & 64.5 & 2.0 \\
\hline 2 & 20 & 2117 & 29454 & 309607 & 10751 & 112602 & 10415 & 109432 & 63.5 & 3.2 & 63.6 & 2.9 \\
\hline 3 & 20 & 2505 & 35189 & 369556 & 11553 & 120718 & 11115 & 116614 & 67.2 & 3.9 & 67.3 & 3.5 \\
\hline 4 & 20 & 2950 & 39880 & 418905 & 13049 & 136990 & 12824 & 134639 & 67.3 & 1.8 & 67.3 & 1.7 \\
\hline 5 & 20 & 3105 & 40046 & 420390 & 13359 & 139962 & 13175 & 138129 & 66.6 & 1.4 & 66.7 & 1.3 \\
\hline Average & 20 & 2612 & 38762 & 412673 & 13259 & 140792 & 12948 & 137734 & 65.8 & 2.4 & 65.9 & 2.2 \\
\hline 1 & 30 & 4264 & 92829 & 1019536 & 24392 & 265799 & 23375 & 256611 & 73.7 & 4.4 & 73.9 & 3.6 \\
\hline 2 & 30 & 3403 & 41954 & 440745 & 13370 & 139359 & 12773 & 133943 & 68.1 & 4.7 & 68.4 & 4.0 \\
\hline 3 & 30 & 4311 & 58879 & 619002 & 17596 & 184124 & 17088 & 179349 & 70.1 & 3.0 & 70.3 & 2.7 \\
\hline 4 & 30 & 4395 & 56509 & 591982 & 17503 & 182680 & 16927 & 177231 & 69.0 & 3.4 & 69.1 & 3.1 \\
\hline 5 & 30 & 5211 & 70052 & 735146 & 20446 & 214029 & 20087 & 210715 & 70.8 & 1.8 & 70.9 & 1.6 \\
\hline Average & 30 & 4317 & 64045 & 681282 & 18661 & 197198 & 18050 & 191570 & 70.4 & 3.4 & 70.5 & 3.0 \\
\hline 1 & 40 & 4587 & 85803 & 939534 & 23965 & 260657 & 23201 & 253691 & 72.1 & 3.3 & 72.3 & 2.7 \\
\hline 2 & 40 & 4102 & 56579 & 594815 & 14639 & 153083 & 14108 & 148151 & 74.1 & 3.8 & 74.3 & 3.3 \\
\hline 3 & 40 & 4525 & 61550 & 646331 & 16472 & 171915 & 15906 & 166846 & 73.2 & 3.6 & 73.4 & 3.0 \\
\hline 4 & 40 & 5017 & 60615 & 638108 & 18697 & 195657 & 18036 & 189622 & 69.2 & 3.7 & 69.3 & 3.2 \\
\hline 5 & 40 & 6114 & 78652 & 827823 & 21955 & 229782 & 21107 & 221886 & 72.1 & 4.0 & 72.2 & 3.6 \\
\hline Average & 40 & 4869 & 68640 & 729322 & 19146 & 202219 & 18472 & 196039 & 72.1 & 3.7 & 72.3 & 3.2 \\
\hline 1 & 50 & 5229 & 71271 & 748970 & 16955 & 177479 & 16518 & 173391 & 76.2 & 2.6 & 76.3 & 2.4 \\
\hline 2 & 50 & 5965 & 72344 & 757081 & 21052 & 218680 & 20279 & 211847 & 70.9 & 3.8 & 71.1 & 3.2 \\
\hline 3 & 50 & 6000 & 83468 & 878691 & 21301 & 222528 & 20231 & 212648 & 74.5 & 5.3 & 74.7 & 4.6 \\
\hline 4 & 50 & 7342 & 95221 & 999281 & 25004 & 260790 & 23868 & 250325 & 73.7 & 4.8 & 73.9 & 4.2 \\
\hline 5 & 50 & 9443 & 197019 & 2166463 & 45235 & 494462 & 43922 & 482950 & 77.0 & 3.0 & 77.2 & 2.4 \\
\hline Average & 50 & 6796 & 103865 & 1110097 & 25909 & 274788 & 24964 & 266232 & 74.5 & 3.9 & 74.6 & 3.4 \\
\hline
\end{tabular}


Table 3: The Performance of the C-DSS-URTS for LD-ABD problem in Comparison with Proposed (0-1) ILP Model

\begin{tabular}{|c|c|c|c|c|c|c|c|c|c|c|c|}
\hline \multirow[t]{2}{*}{ Run } & \multicolumn{2}{|c|}{ Depot Details } & \multicolumn{3}{|c|}{ Bus Details } & \multicolumn{3}{|c|}{ Terminus Details } & \multirow{2}{*}{$\begin{array}{l}\text { Total Cost in } \\
\text { Rs. by C- } \\
\text { DSS-URTS }\end{array}$} & \multirow{2}{*}{$\begin{array}{c}\text { Optimal } \\
\text { Cost in Rs. } \\
\text { by ILP } \\
\text { Model }\end{array}$} & \multirow{2}{*}{$\begin{array}{c}\text { Loss of } \\
\text { Optimality in } \\
\text { Percentage }\end{array}$} \\
\hline & $\begin{array}{l}\text { Existing \# of } \\
\text { Depots }\end{array}$ & $\begin{array}{l}\text { Total \# of } \\
\text { Depots for } \\
\text { the Run }\end{array}$ & $\begin{array}{c}\# \text { of Existing } \\
\text { Buses }\end{array}$ & $\begin{array}{c}\text { \# of New } \\
\text { Buses }\end{array}$ & $\begin{array}{c}\text { Total \# of } \\
\text { Buses for the } \\
\text { Run } \\
\end{array}$ & $\begin{array}{c}\text { \# of Existing } \\
\text { Terminus }\end{array}$ & $\begin{array}{l}\text { \# of New } \\
\text { Terminus }\end{array}$ & $\begin{array}{c}\text { Total \# of } \\
\text { Terminus for } \\
\text { the Run }\end{array}$ & & & \\
\hline 1 & 10 & 11 & 1335 & 30 & 1365 & 130 & 7 & 137 & 8896054 & 8716485 & 2.1 \\
\hline 2 & 10 & 11 & 1058 & 30 & 1088 & 60 & 5 & 65 & 8874518 & 8871357 & 0.0 \\
\hline 3 & 10 & 11 & 1255 & 30 & 1285 & 72 & 6 & 78 & 9086995 & 9084817 & 0.0 \\
\hline 4 & 10 & 11 & 1463 & 33 & 1496 & 75 & 6 & 81 & 9355308 & 9352283 & 0.0 \\
\hline 5 & 10 & 11 & 1501 & 36 & 1537 & 81 & 30 & 111 & 9913680 & 9909729 & 0.0 \\
\hline Average & & & & & & & & & 9225311 & 9186934 & 0.4 \\
\hline 1 & 20 & 21 & 2384 & 24 & 2408 & 130 & 7 & 137 & 8935986 & 8934752 & 0.0 \\
\hline 2 & 20 & 21 & 2117 & 111 & 2228 & 82 & 25 & 107 & 10360623 & 10149890 & 2.1 \\
\hline 3 & 20 & 21 & 2505 & 69 & 2574 & 80 & 28 & 108 & 9790410 & 9782635 & 0.1 \\
\hline 4 & 20 & 21 & 2950 & 84 & 3034 & 130 & 30 & 160 & 10048782 & 9773304 & 2.8 \\
\hline 5 & 20 & 21 & 3105 & 111 & 3216 & 120 & 35 & 135 & 9657940 & 9648309 & 0.1 \\
\hline Average & & & & & & & & & 9758748 & 9657778 & 1.0 \\
\hline 1 & 30 & 31 & 4264 & 45 & 4309 & 140 & 15 & 155 & 10379542 & 9647311 & 7.6 \\
\hline 2 & 30 & 31 & 3403 & 111 & 3514 & 110 & 27 & 137 & 10457121 & 10447480 & 0.1 \\
\hline 3 & 30 & 31 & 4311 & 111 & 4422 & 140 & 35 & 175 & 10857723 & 10616520 & 2.3 \\
\hline 5 & 30 & 31 & 5211 & 120 & 5331 & 140 & 40 & 180 & 9842127 & 9831332 & 0.1 \\
\hline Average & & & & & & & & & 10355289 & 10098006 & 2.5 \\
\hline 1 & 40 & 41 & 4587 & 54 & 4641 & 130 & 28 & 158 & 10253960 & 9977648 & 2.8 \\
\hline 2 & 40 & 41 & 4102 & 75 & 4177 & 100 & 25 & 125 & 9707584 & 9695180 & 0.1 \\
\hline 3 & 40 & 41 & 4525 & 120 & 4675 & 110 & 30 & 140 & 10178707 & 9722287 & 4.7 \\
\hline 4 & 40 & 41 & 5017 & 105 & 5122 & 105 & 35 & 140 & 10730855 & 10719450 & 0.1 \\
\hline 5 & 40 & 41 & 6114 & 120 & 6234 & 140 & 130 & 270 & 11121122 & 10877390 & 2.2 \\
\hline Average & & & & & & & & & 10398446 & 10198391 & 2.0 \\
\hline 1 & 50 & 51 & 5229 & 111 & 5340 & 120 & 110 & 230 & 10321261 & 10305710 & 0.2 \\
\hline 2 & 50 & 51 & 5965 & 105 & 6070 & 85 & 30 & 115 & 10972387 & 10342290 & 6.1 \\
\hline 3 & 50 & 51 & 6000 & 105 & 6105 & 95 & 28 & 123 & 10316719 & 10302580 & 0.1 \\
\hline 4 & 50 & 51 & 7342 & 129 & 7471 & 120 & 55 & 172 & 10588091 & 10570880 & 0.2 \\
\hline 5 & 50 & 51 & 9443 & 66 & 9509 & 150 & 30 & 180 & 10824945 & 10809600 & 0.1 \\
\hline Average & & & & & & & & & 10604681 & 10466212 & 1.3 \\
\hline
\end{tabular}

Note: For all the 25 Problem Instances, the data values for (a) Number of Possible Existing Depots to be closed from the existing ones : 02, (b) Number of Existing Depots exactly to be closed : 01 , (c) Number of Feasible New Depots to be Opened : 03, and (d) Number of Feasible New Depots exactly to be Opened : 02. However, the choice of 'number of possible existing depots to be closed' among the existing ones is assumed to be randomly decided. 
Apart from prescribing the near optimal/efficient locations for depots and allocation of buses to the depots by minimizing cost of operations, particularly minimizing the dead-kilometer cost, the UTRS could reasonable estimates the cost savings for the extent of pollutant emissions and energy consumption caused due to the dead-kilometers to be incurred based on the optimal/efficient decisions of the location of depots and allocations of buses to depots in comparison with existing practice.

The proposed C-DSS-URTS designed and implemented for obtaining optimal decision for ABD or LD-ABD problem has significant advantages. It reduces the deployment and processing time, provides learning feature for the decision makers by carrying out What-if analyses, facilitates the accessibility, and decrease the operational cost, including the capital expenditures. The proposed CDSS-URTS for obtaining optimal decision for ABD or LD-ABD problem also has some other advantages. For example, it is accessible at any time and from anywhere by any URTS by using a browser via the Internet and thus these will prompt users to participate in the decision-making processes. It is easy to maintain and upgrade, as the system is deployed on the public cloud: Amazon's cloud services. However, in the prototype C-DSS-URTS, the today's real management practices in taking the decisions on (a) ABD, and (b) LD-ABD are not considered.

The novelties of the proposed C-DSS-URTS are that the DSS cloud and Web service-based architecture is easy to manage and update, able to provide flexibility in information exchange operations among the cooperative partners. In this context, the proposed prototype C-DSS-URTS acts as an independent entity that collects all the relevant data and provides decisions to the decision maker, in order to improve the performances, thus improving the specific objective of minimizing the cost of the bus operation.

\section{Conclusion}

This paper presents architecture of a Cloud-based DSS (C-DSS) that integrates the strategic problem on location of depots (for adding new locations and removing existing ones) and allocation of buses to depots (LD-ABD), as observed in an Indian Urban Road Transport System for optimizing the cost of bus operations. Furthermore, the proposed C-DSS-URTS is developed using latest web technologies with a user-friendly web interface which can be used in any browser. Precisely the proposed C-DSSURTS is developed as a SaaS (Software as a Service) model in the cloud and it is currently deployed in Amazon Web Services (AWS Cloud), which enables the users to access it using from anywhere using any devices. The proposed C-DSS-URTS has some advantages such as (a) quasi-real-time decision is obtained by utilizing cloud computing technology, (b) an intuitive and user friendly GUI is provided to enhance the user experience, (c) it is very economic, as the C- 
DSS-URTS is entirely built on efficient heuristic algorithms, and this feature lends to it great prospects of being applied to other URTS.

It is to be highlighted that this study is at an initial stage of the development cycle, and the proposed prototype C-DSS-URTS for obtaining optimal decision for LD-ABD problem is mainly for the purpose of demonstrating to and communicating with URTS for its easy utility and stimulating them to provide more specific and accurate system demands for further enhancements. That is, the proposed prototype C-DSS-URTS has some inadequacies related to the assumptions (e.g., any bus can be allocated to any available depot, depot operating cost is same across the depot for every bus, etc.,), considered in this study, for developing solution methodologies and thus, continuous improvement is necessary. In the next version of C-DSS-URTS, more management practices will be incorporated as immediate further research scope of the problem addressed here.

\section{REFERENCES}

1. Akunal, E.V.O. 2016. Decision Support Systems in Transport Planning. Procedia Engineering $161,1119-1126$.

2. Agarwal, R., and Dhingra, S. 2018. Cloud Computing in India: Issues and Challenges, Consulting Ahead, Vol. 12, No. 1, pp. 23-35.

3. Arampatzis, G., Kiranoudis, C.T., Scaloubacas, P., Assimacopoulos, D. 2014. A GIS-based decision support system for planning urban transportation policies. European Journal of Operational Research, 152, 465-475.

4. Arbex, R.O., and Cunha, C.B.D. (2015). Efficient transit network design and frequencies setting multi-objective optimization by alternating objective genetic algorithm. Transportation Research Part B, 81, 355-376

5. Armbrust, M, Fox, A., Griffith, R., Joseph, A.D., Katz, R., Konwinski, A., Lee, G., Patterson, D., Rabkin, A., Stoica, I., and Zaharia, M. (2010). A View of Cloud Computing. Communications of the ACM, 53(4), 50-58.

6. Ashokkuma, K., Baron Sam, Arshadprabhu, R., and Britto. 2015. CLOUD BASED INTELLIGENT TRANSPORT SYSTEM. Procedia Computer Science, 50, 58 - 63

7. Bielli, M. 1992. “A DSS Approach to Urban Traffic Management," European Journal of Operational

8. Research, Volume 61, pp.106-113.

9. Canellos, D., 2013. How the Internet of Things will Feed Cloud Computing next Evolution, 2013, (Available online: https://blog.cloudsecurityalliance.org/2013/06/05/how-the-internetof-things-will-feed-cloud-computings-next-evolution/ accessed on $1^{\text {st }}$ October 2018)

10. Farahani, R.Z., Miandoabchi, E., Szeto, W.Y. Rashidi, H. (2013).A review of urban transportation network design problems, European Journal of Operational Research, 229(2), 281-302. 
11. Guihaire, V., and Hao, Jin-Kao. (2008). Transit network design and scheduling: A global review. Transportation Research Part A, 42, 1251-1273

12. Harris, I., Wang, Y., \& Wang, H. (2015). ICT in multimodal transport and technological trends: Unleashing potential for the future. International Journal of Production Economics, 159, 88-103.

13. Hasai, M.K. 2010. A Framework for Intelligent Decision Support Systems for Traffic Congestion Management System. Engineering, Vol. 2 No. 4, pp. 270-289. doi: $10.4236 /$ eng.2010.24037.

14. Hsu, Chia-Yu \& Yang, Chin-Sheng \& Yu, Liang-Chih \& Lin, Chi-Fang \& Yao, Hsiu-Hsen \& Chen, Duan-Yu \& Robert Lai, K. \& Chang, Pei-Chann, 2015. "Development of a cloud-based service framework for energy conservation in a sustainable intelligent transportation system," International Journal of Production Economics, Vol. 164(C), pp. 454-461

15. Ibarra-Rojas, O.J., Delgado, F., Giesen, R., Muñoz, J.C. (2015). Planning, operation, and control of bus transport systems: A literature review. Transportation Research Part B, 77, 3875.

16. Jaworski, P., Edwards, T., Moore, J., and Burnham, K. (2011). Cloud Computing Concept for Intelligent Transportation Systems. 2011 14th International IEEE Conference on Intelligent Transportation Systems Washington, DC, USA. October 5-7 (Available online: https://ieeexplore.ieee.org/stamp/stamp.jsp?tp=\&arnumber $=6083087$ accessed on $1^{\text {st }}$ October 2018)

17. Jun, L., and Jun, W. 2011. Cloud Computing based Solution to Decision Making. Procedia Engineering 15, 1822-1826.

18. Jun, D., Kieki, MO. 2009. and Intelligent Decision Support System for Road Network Planning. 2009 ISECS International Colloquium on Computing, Communication, Control, and Management (Available online: https://ieeexplore.ieee.org/stamp/stamp.jsp?tp=\&arnumber $=5267809 \quad$ accessed on $1^{\text {st }}$ October 2018)

19. Kepaptsoglou, K., Karlaftis, M., (2009). Transit route network design problem: review. Journal of Transportation Engineering, 135(8), 491-505.

20. Kepaptsoglou, K., Karlaftis, M. G., and Bitsikas, T. (2010). Bus-to-Depot Allocation: Models and Decision Support System. Journal of Transportation Engineering, 136(7), 600-605

21. Kontou, E., Kepaptsoglou, K., and Charalampakis, A.E. (2014). The bus to depot allocation problem revisited: a genetic algorithm. Public Transportation, 6, 237-255.

22. Kurian, A., and Jian. M. 2017. Quality Vision Technology Based Delhi Bus Transportation Management Decision Support System. International Journal of Advances in Agricultural \& Environmental Engineering, Vol. 4, Issue 1, pp. 173-177.

23. Leimeister, S., Böhm, M., Christoph Riedl, C., and Krcmar, H. (2010). The Business Perspective of Cloud Computing: Actors, Roles and Value Networks. 18th European Conference on Information Systems (Available online: https://aisel.aisnet.org/cgi/viewcontent.cgi?article $=1082 \&$ context=ecis 2010 accessed on $1^{\text {st }}$ October, 2018) 
24. Marston, S., Li, Z., Bandyopadhyay, S., Zhang, J., and Ghalsasi, A. (2011). Cloud computing - The business perspective. Decision Support Systems 5, 176-189.

25. Mathirajan, M. (1993). An efficient heuristic for minimizing dead-kilometres in Urban Transport Systems. Journal of Transport Management, 17, 125-133.

26. Mathirajan, M., Hariharakrishnan, C. V., and Ramachandran, V. (2010). An experimental evaluation of heuristic algorithms for bus-depot matching problem of urban road transport systems. OPSEARCH, 47(2), 143-157.

27. Mathirajan, M., Suba, P., and Ramakrishnan Ramanthan. (2018). Location of Depots and Allocation of Buses to Depots in Urban Road Transport Organizations: A Mathematical Modal and Greedy Heuristic Algorithm. International Journal of Operational Research. In print.

28. Meneguette, R.I. (2016). A Vehicular Cloud-Based Framework for the Intelligent Transport Management of Big Cities. International Journal of Distributed Sensor Networks Volume 2016, Article ID 8198597, 9 pages.

29. Mell, P. and Grance, T. (2011). The NIST definition of cloud computing recommendations of the national institute of standards and technology. Special publication 800145. (Available online: $\quad$ http://nvlpubs.nist.gov/nistpubs/Legacy/SP/nistspecialpublication800-145.pdf. [accessed on 25 March 2017

30. Raghavendra, B.G. and Mathirajan, M. (1987). Optimal allocation of buses to depots: A case study. OPSEARCH, 24(4), 228-239.

31. Roy, S., Jagan, J., and Samui, P. (2016). Determination of Work Zone Capacity Using ELM, MPMR and GPR, in E.V. Ocalir-Akunal (Ed), Using Decsion Support System for Transport Planning Efficiency, pp. 93-116.

32. Russell, S., Yoon, V, and Forgionne, G. 2010. Cloud-based Decision Support Systems and Availability Context: The Probability of Successful Decision Outcomes. Information Systems and e-Business Management, 8, 189-205.

33. Saric, S., Perakovic, D., and Irena, K. 2012. "Possibility Of Improving Passenger Information System In Bus Transport Using Cloud Services," Proceedings of International Scientific Conference Development of Logistics Business and Transport System Supported by EU Funds / Pavlin, Stanislav ; Šafran, Mario (ur.). - Zagreb: University of Zagreb, Faculty of Transport and Traffic Sciences , pp. 241-249. (Available online: https://bib.irb.hr/datoteka/580452.29_-

_Possibility_of_Improving_Passenger_Information_System.pdf - Accessed on $30^{\text {th }}$ June, 2018 )

34. Shulesk, D., Birsan, A., Veronica Cristea, C., and Radu, I. (2016). IMPACT OF CLOUD COMPUTING TECHNOLOGY IMPLEMENTATION IN PUBLIC SECTOR. PROCEEDINGS OF THE 10th INTERNATIONAL MANAGEMENT CONFERENCE "Challenges of Modern Management", November 3rd-4th, 2016, BUCHAREST, ROMANIA (Available online: http://conferinta.management.ase.ro/archives/2016/PDF/3 14.pdf accessed on $1^{\text {st }}$ October, 2018)

35. Tan, M.C., Tong, C.O. and Xu, J.M. 2004. Study and Implementation of a Decision Support System for Urban Mass Transit Service Planning. Journal of Information Technology Management, Volume XV, Numbers 1-2, pp. 14-32. 
36. Turban, E., and Aroson, J.E. (1998). Decision Support Systems and Intelligent Systems (5 ${ }^{\text {th }}$ Edition). Prentice Hall International editions

37. Utama, D.N., Zaki, F.A., Munjeri, I.J. and Putri, N.U. 2017. FWFA Optimization based Decision Support System for Road Traffic Engineering. Journal of Physics: Conference Series, vol. 801, pp. 012016,

38. Weinhardt, C., Anandasivam, A., Blau, B., Borissov, N., Meinl, T., Michalk, W., and Stößer, J.. (2009). Cloud Computing - A Classification, Business Models, and Research Directions. Business \& Information Systems Engineering. Vol. 1, No. 5, pp 391-399

39. Willoughby, K.A., Uyeno, D.H. (2001). Resolving splits in location/allocation modeling: a heuristic procedure for transit center decisions, Transportation Research Part E: Logistics and Transportation Review, 37(1), 71-83.

40. Winston, W.L. (1993). Operations Research: Applications and Algorithms (3 ${ }^{\text {rd }}$ Edition). Duxbury Press, Belmont, California. 


\section{Annexure 1}

\section{$\underline{\text { A Proposed Cloud architecture for C-DSS-URTS }}$}

The proposed DSS is developed using latest web technologies like Angular.js, PHP, HTML and CSS with a backend MySQL database. This is deployed in the cloud infrastructure using Amazon Web Services (AWS). The following figure shows deployment architecture for this web based DSS system which is deployed over the internet for easy access.

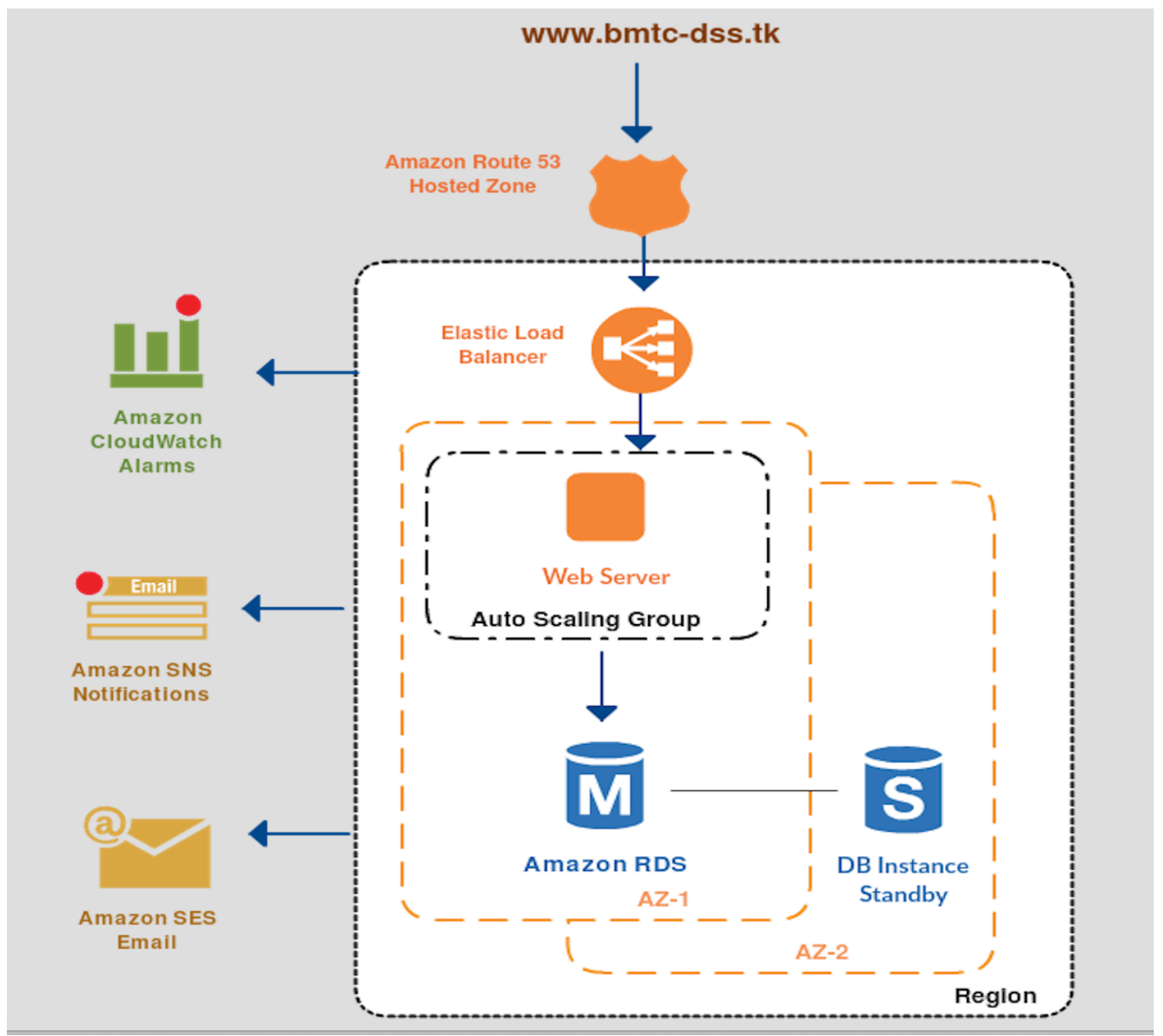

The architecture considered is based on simple 2-tiers architecture with web layer and database layer. The web application is integrated with cloud watch, notification module and email module for external communication. The database is deployed in failover mode with two instances one as master and the other in standby mode. 
Annexure 2

Input Tables and Output Tables Structure of C-DSS-URTS

\begin{tabular}{|c|c|c|c|c|c|c|}
\hline$\#$ & Name & Type & Collation & Attributes & Null & Default \\
\hline 1 & serialno 屓 & $\operatorname{int}(11)$ & & & No & None \\
\hline 2 & code & varchar(20) & utf8_unicode_ci & & No & None \\
\hline 3 & name & $\operatorname{varchar}(40)$ & utf8_unicode_ci & & No & None \\
\hline 4 & division & varchar(5) & utf8_unicode_ci & & No & None \\
\hline 5 & current_capacity & $\operatorname{int}(11)$ & & & No & None \\
\hline 6 & maximum_capacity & $\operatorname{int}(11)$ & & & No & None \\
\hline 7 & whatif_capacity & $\operatorname{int}(4)$ & & & No & None \\
\hline 8 & operating_cost & $\operatorname{int}(11)$ & & & No & None \\
\hline 9 & salvage_cost & $\operatorname{int}(11)$ & & & No & None \\
\hline 10 & fixed_cost & float & & & No & None \\
\hline 11 & org_code & varchar(20) & utf8_unicode_ci & & No & None \\
\hline 12 & purpose & $\operatorname{int}(2)$ & & & No & None \\
\hline
\end{tabular}

Exhibit 1: The structure of "Depot-Table" in DMM

\begin{tabular}{|c|c|c|c|c|c|c|}
\hline$\#$ & Name & Type & Collation & Attributes & Null & Default \\
\hline 1 & id 屓行 & $\operatorname{int}(11)$ & & & No & None \\
\hline 2 & terminus_code & varchar(20) & utf8_unicode_ci & & No & None \\
\hline 3 & terminus_name & varchar(50) & utf8_unicode_ci & & No & None \\
\hline 4 & org_code & varchar(20) & utf8_unicode_ci & & No & None \\
\hline 5 & purpose & int(2) & & & No & None \\
\hline
\end{tabular}

Exhibit 2: The structure of "Terminus Table" in DMM

\begin{tabular}{|l|l|l|l|l|l|l|}
\hline$\#$ & \multicolumn{1}{|c|}{ Name } & \multicolumn{1}{|c|}{ Type } & \multicolumn{1}{|c|}{ Collation } & Attributes & Null & Default \\
\hline 1 & id 自: & int(11) & & No & None \\
\hline 2 & terminus_code & varchar(20) & utf8_unicode_ci & No & None \\
\hline 3 & depot_code & varchar(20) & utf8_unicode_ci & No & None \\
\hline 4 & distance & float & & No & None \\
\hline 5 & org_code & varchar(20) & utf8_unicode_ci & No & None \\
\hline 6 & purpose & int(2) & & No & None \\
\hline
\end{tabular}

Exhibit 3: The structure of "Terminus-Depot Table" in DMM 


\begin{tabular}{|c|c|c|c|c|c|c|}
\hline$\#$ & Name & Type & Collation & Attributes & Null & Default \\
\hline 1 & id 唒] & $\operatorname{int}(5)$ & & & No & None \\
\hline 2 & route_no & $\operatorname{varchar}(10)$ & utf8_unicode_ci & & No & None \\
\hline 3 & depot_code & $\operatorname{varchar}(10)$ & utf8_unicode_ci & & No & None \\
\hline 4 & terminus_start & $\operatorname{varchar}(50)$ & utf8_unicode_ci & & No & None \\
\hline 5 & terminus_end & $\operatorname{varchar}(50)$ & utf8_unicode_ci & & No & None \\
\hline 6 & fuel_cost_km & $\operatorname{int}(2)$ & & & No & None \\
\hline 7 & org_code & varchar(20) & utf8_unicode_ci & & No & None \\
\hline 8 & purpose & $\operatorname{int}(2)$ & & & No & None \\
\hline
\end{tabular}

Exhibit 4 : The structure of "Bus Table" in DMM

\begin{tabular}{|l|l|l|l|l|l|l|}
\hline \# & \multicolumn{1}{|c|}{ Name } & \multicolumn{1}{|c|}{ Type } & \multicolumn{1}{|c|}{ Collation } & Attributes & Null & Default \\
\hline 1 & id 圆i & int(11) & & No & None \\
\hline 2 & route_no & varchar(10) & utf8_unicode_ci & No & None \\
\hline 3 & depot_code & varchar(20) & utf8_unicode_ci & No & None \\
\hline 4 & remarks & text & utf8_unicode_ci & No & None \\
\hline 5 & org_code & varchar(20) & utf8_unicode_ci & No & None \\
\hline 6 & purpose & int(2) & & No & None \\
\hline
\end{tabular}

Exhibit 5: The structure of "Route-Depot Constraints Table" in DMM

\begin{tabular}{|c|c|c|c|c|c|c|}
\hline$\#$ & Name & Type & Collation & Attributes & Null & Default \\
\hline 1 & id 唒通 & $\operatorname{int}(11)$ & & & No & None \\
\hline 2 & depot_code & varchar(15) & utf8_unicode_ci & & No & None \\
\hline 3 & route_no & varchar(20) & utf8_unicode_ci & & No & None \\
\hline 4 & org_code & varchar(20) & utf8_unicode_ci & & No & None \\
\hline 5 & purpose & $\operatorname{int}(11)$ & & & No & None \\
\hline
\end{tabular}

Exhibit 6: The structure of "Result Table" in DMM

\begin{tabular}{|c|c|c|c|c|c|c|}
\hline$\#$ & Name & Type & Collation & Attributes & Null & Default \\
\hline 1 & id 閔 & $\operatorname{int}(11)$ & & & No & None \\
\hline 2 & depot_codes_closing & $\operatorname{varchar}(100)$ & utf8_unicode_ci & & No & None \\
\hline 3 & depot_close_possible & $\operatorname{int}(2)$ & & & No & None \\
\hline 4 & depot_close_exact & $\operatorname{int}(2)$ & & & No & None \\
\hline 5 & depot_open_possible & $\operatorname{int}(2)$ & & & No & None \\
\hline 6 & depot_open_exact & $\operatorname{int}(2)$ & & & No & None \\
\hline 7 & num_buses & $\operatorname{int}(3)$ & & & No & None \\
\hline 8 & org_code & varchar(5) & utf8_unicode_ci & & No & None \\
\hline
\end{tabular}

Exhibit 7: The structure of "LD-ABD Table" in DMM 


\begin{tabular}{|c|c|c|c|c|c|c|c|c|}
\hline \multirow[b]{2}{*}{ Bus No } & \multirow[b]{2}{*}{ Start Terminus } & \multirow[b]{2}{*}{ End Terminus } & \multicolumn{3}{|c|}{ Existing Allocation } & \multicolumn{3}{|c|}{ Allocation by C-DSS } \\
\hline & & & Depot & Distance & Cost & Depot & Distance & Cost \\
\hline R1 & SBS & BBS & D1 & 18.5 & 203.5 & D1 & 18.2 & 200.2 \\
\hline R2 & CMT & CMT & D1 & 8 & 96 & D3 & 8 & 96 \\
\hline R3 & MBS & BBS & D1 & 17.3 & 190.3 & D2 & 14.8 & 162.8 \\
\hline R4 & GNR & SNR & D2 & 16.6 & 182.6 & D2 & 9.4 & 103.4 \\
\hline R5 & SNR & GNR & D2 & 16.6 & 199.2 & D2 & 9.4 & 112.8 \\
\hline R6 & GNR & GNR & D2 & 15.2 & 152 & D2 & 8 & 80 \\
\hline R7 & BBS & SBS & D2 & 18.5 & 222 & D1 & 18.2 & 218.4 \\
\hline R8 & CMT & BBS & D2 & 15 & 165 & D1 & 15.2 & 167.2 \\
\hline R9 & BBS & SBS & D2 & 18.5 & 222 & D2 & 19 & 228 \\
\hline R10 & CMT & BBS & D2 & 15 & 150 & D3 & 15 & 150 \\
\hline R11 & MBS & SBS & D3 & 13.8 & 151.8 & D3 & 13.8 & 151.8 \\
\hline R12 & MBS & MBS & D3 & 12.6 & 138.6 & D2 & 11.6 & 127.6 \\
\hline $\mathrm{R} 13$ & CMT & SBS & D3 & 11.5 & 138 & D3 & 11.5 & 138 \\
\hline $\mathrm{R} 14$ & SNR & BBS & D3 & 20 & 240 & D2 & 14.4 & 172.8 \\
\hline R15 & CMT & SBS & D3 & 11.5 & 115 & D3 & 11.5 & 115 \\
\hline & & & & 228.6 & 2566 & & 198 & 2224 \\
\hline
\end{tabular}

Exhibit 8: A Sample Output Generated from C-DSS-URTS for "Bus Status Report"

\begin{tabular}{|c|c|c|c|c|c|c|c|c|c|}
\hline & & & & & & & & Depo & \\
\hline Sl. No & Bus No & Start Terminus & Distance & End Terminus & Distance & Fuel Cost & Dead Kilometer Cost & DSS & Existing \\
\hline 2 & R1 & SBS & 8 & BBS & 10.2 & 11 & 200.2 & D1 & D1 \\
\hline 3 & R7 & BBS & 10.2 & SBS & 8 & 12 & 218.4 & D1 & D2 \\
\hline 5 & R5 & SNR & 5.4 & GNR & 4 & 12 & 112.8 & D2 & D2 \\
\hline 6 & R4 & GNR & 4 & SNR & 5.4 & 11 & 103.4 & D2 & D2 \\
\hline 7 & $\mathrm{R} 12$ & MBS & 5.8 & MBS & 5.8 & 11 & 127.6 & D2 & D3 \\
\hline 10 & R9 & BBS & 9 & SBS & 10 & 12 & 228 & D2 & D2 \\
\hline 11 & R2 & CMT & 4 & CMT & 4 & 12 & 96 & D3 & D1 \\
\hline 12 & R15 & CMT & 4 & SBS & 7.5 & 10 & 115 & D3 & D3 \\
\hline 13 & R11 & MBS & 6.3 & SBS & 7.5 & 11 & 151.8 & D3 & D3 \\
\hline 14 & $\mathrm{R} 13$ & CMT & 4 & SBS & 7.5 & 12 & 138 & D3 & D3 \\
\hline 15 & $\mathrm{R} 10$ & CMT & 4 & BBS & 11 & 10 & 150 & D3 & D2 \\
\hline
\end{tabular}

Exhibit 9: A Sample Output Generated from C-DSS-URTS for "Bus Allocation Report" 


\section{Depot:D1 - Depot1}

\begin{tabular}{|l|l|l|l|l|}
\hline Route No & Start Terminus & End Terminus & To Depot & From Depot \\
\hline R1 & SBS & BBS & - & - \\
\hline R2 & CMT & CMT & D3 & - \\
\hline R3 & MBS & BBS & D2 & - \\
\hline R8 & CMT & BBS & - & D2 \\
\hline R7 & BBS & SBS & - & D2 \\
\hline
\end{tabular}

Exhibit 10: A Sample Output Generated from C-DSS-URTS for "Depot wise Change Summary Report"

\section{Summary Report}

Depot-wise summary details
\begin{tabular}{|l|l|l|l|l|l|l|l|l|}
\hline & \multicolumn{9}{l|}{ Existing Allocation } & \multicolumn{3}{l|}{ Efficient Allocation } \\
\hline Depot Code & Depot Name & \# buses & Dead kms & Cost & \# buses & Dead kms & Cost \\
\hline D1 & Depot1 & 3 & 43.80 & 489.80 & 3 & 51.60 & 585.80 \\
\hline D2 & Depot2 & 7 & 115.40 & 1292.80 & 7 & 86.60 & 987.40 \\
\hline D3 & Depot3 & 5 & 69.40 & 783.40 & 5 & 59.80 & 650.80 \\
\hline Total & & 15 & 228.60 & 2566.00 & 15 & 198.00 & 2224.00 \\
\hline
\end{tabular}

Exhibit 11: A Sample Output Generated from C-DSS-URTS for "Summary Report" 


\section{Annexure 3}

\section{A Greedy Heuristic Algorithm for LD-ABD Problem of Indian URTSs}

The step by step approach of the extended greedy heuristic algorithm, proposed in Mathirajan et al. (2018), is as follows:

Step 1: Let 'Combination' $=0$

Step 2: Select a combination of existing facilities [after considering closing facility (or facilities) combination] and new facility (or facilities) [after considering opening facility (or facilities) combination]. And assign Combination $=$ Combination +1

Step 3: Compute Facilities Cost for the selected combination of existing facility and new facility

Facilities cost $=\left(\begin{array}{c}\text { Fixedcostinvolved } \\ \text { inopeningofnew facility }\end{array}\right)-\left(\begin{array}{c}\text { Revenueobtainedfromclosing } \\ \text { theexisting facility }\end{array}\right)$

Step 4: Using the selected combination of existing and new facilities, allocation of buses to the given set of facilities (depots) is formulated as transportation problem. As Mathirajan et al (2010) empirically proved that the initial basic solution method by Vogel's Approximation Method (VAM) provides near optimal solution, VAM is used for allocation of buses to depots to optimize the total dead-kilometer cost.

Step 5: Compute the Overall Cost for location of depots and allocation of buses to depots for the selected combination of existing and new facility

Overall Cost $($ combination $)=($ Facilities Cost $)+($ Total Dead Kilometer Cost $)$

Step 6: Repeat Step 2 to Step 5 for each possible combinations of existing facilities [after considering closing facility (or facilities) combination] and new facility (or facilities) [after considering opening facility (or facilities) combination].

Step 7: List combination wise the Overall Cost obtained and allow the user to choose the best combination based on the minimum overall cost and decision maker's subjective decision on the combination of existing facilities [after considering closing facility (or facilities) combination] and new facility (or facilities) [after considering opening facility (or facilities) combination].

Step 8: Based on the decision maker's choice on combination of existing and new depots the detailed reports on (a) list of closing depots, (b) list of opening new depots, (c) depot wise the overall summary on number of buses allocated along with the overall cost, (d) allocation of buses to depots are generated. 


\section{Annexure 4}

\section{$\underline{\text { A Numerical Example for Allocation of Buses to Depots (ABD) Problem }}$}

The objective of the numerical example problem given here is to minimize the total dead kilometer cost by optimally allocating the given $\mathrm{N}(=15)$ number of buses to existing $\mathrm{M}(=3)$ number of depots.

\section{$\underline{\text { Existing Bus-Depot Allocation }}$}

Depot 1 : D1

\begin{tabular}{|c|c|c|c|c|c|c|}
\hline $\begin{array}{l}\text { Sl. } \\
\text { No. }\end{array}$ & $\begin{array}{l}\text { Route } \\
\text { No. }\end{array}$ & $\begin{array}{l}\text { Starting } \\
\text { Terminus (ST) }\end{array}$ & $\begin{array}{l}\text { Distance from } \\
\text { ST to Depot }\end{array}$ & $\begin{array}{l}\text { Ending } \\
\text { Terminus (ET) }\end{array}$ & $\begin{array}{l}\text { Distance from } \\
\text { ET to Depot }\end{array}$ & $\begin{array}{l}\text { Fuel Cost } \\
\text { Per KM }\end{array}$ \\
\hline 1 & R1 & SBS & 8.0 & BBS & 10.2 & 11 \\
\hline 2 & R2 & CMT & 5.0 & CMT & 5.0 & 12 \\
\hline 3 & R3 & MBS & 12.0 & BBS & 10.2 & 11 \\
\hline
\end{tabular}

Depot 2 : D2

\begin{tabular}{|c|c|c|c|c|c|c|}
\hline $\begin{array}{c}\text { Sl. } \\
\text { No. }\end{array}$ & $\begin{array}{c}\text { Route } \\
\text { No. }\end{array}$ & $\begin{array}{c}\text { Starting } \\
\text { Terminus (ST) }\end{array}$ & $\begin{array}{c}\text { Distance } \\
\text { from ST to } \\
\text { Depot }\end{array}$ & $\begin{array}{c}\text { Ending } \\
\text { Terminus } \\
(\text { ET })\end{array}$ & $\begin{array}{c}\text { Distance from } \\
\text { ET to Depot }\end{array}$ & $\begin{array}{c}\text { Fuel Cost } \\
\text { Per KM }\end{array}$ \\
\hline 1 & R4 & GNR & 4.0 & SNR & 5.4 & 11 \\
\hline 2 & R5 & SNR & 5.4 & GNR & 4.0 & 12 \\
\hline 3 & R6 & GNR & 4.0 & GNR & 4.0 & 10 \\
\hline 4 & R7 & BBS & 9.0 & SBS & 10.0 & 12 \\
\hline 5 & R8 & CMT & 7.0 & BBS & 9.0 & 11 \\
\hline 6 & R9 & BBS & 9.0 & SBS & 10.0 & 12 \\
\hline 7 & R10 & CMT & 7.0 & BBS & 9.0 & 10 \\
\hline
\end{tabular}

Depot 3 : D3

\begin{tabular}{|c|c|c|c|c|c|c|}
\hline $\begin{array}{l}\text { Sl. } \\
\text { No. }\end{array}$ & Route No. & $\begin{array}{l}\text { Starting } \\
\text { Terminus } \\
\text { (ST) }\end{array}$ & $\begin{array}{l}\text { Distance } \\
\text { from ST to } \\
\text { Depot }\end{array}$ & $\begin{array}{l}\text { Ending } \\
\text { Terminus } \\
\text { (ET) }\end{array}$ & $\begin{array}{l}\text { Distance from } \\
\text { ET to Depot }\end{array}$ & $\begin{array}{l}\text { Fuel Cost } \\
\text { Per KM }\end{array}$ \\
\hline 1 & R11 & MBS & 6.3 & SBS & 7.5 & 11 \\
\hline 2 & R12 & MBS & 6.3 & MBS & 6.3 & 11 \\
\hline 3 & R13 & CMT & 4.0 & SBS & 7.5 & 12 \\
\hline 4 & R14 & SNR & 9.0 & BBS & 11.0 & 12 \\
\hline 5 & R15 & CMT & 4.0 & SBS & 7.5 & 10 \\
\hline
\end{tabular}

\section{Distance between Starting/Ending Terminus and Depot}

\begin{tabular}{|l|l|c|c|c|}
\hline \multirow{2}{*}{$\begin{array}{l}\text { Terminus } \\
\text { Code }\end{array}$} & Terminus Name & \multicolumn{3}{|c|}{ Distance from 'Terminus' to the } \\
& & \multicolumn{3}{|c|}{ Depot } \\
\cline { 3 - 4 } & & $\mathrm{D} 1$ & $\mathrm{D} 2$ & $\mathrm{D} 3$ \\
\hline BBS & Bangalore Bus Station & 10.2 & 9.0 & 11.0 \\
\hline CMT & City Market & 5.0 & 7.0 & 4.0 \\
\hline GNR & Gandhi Nagar & 9.4 & 4.0 & 7.6 \\
\hline MBS & Malleswaram Bus Station & 12.0 & 5.8 & 6.3 \\
\hline SBS & Shivajinagar Bus Station & 8.0 & 10.0 & 7.5 \\
\hline SNR & Srinagar & 5.0 & 5.4 & 9.0 \\
\hline
\end{tabular}

\# This is a Crucial Input Data and generally this complete data is not be available in URTS in India [However, this is possible to generate this data if GIS is used in URTS] 


\section{Annexure 4 (Contd.)}

\section{A Numerical Example for Location of Depots and ABD (LD-ABD) problem}

The numerical example for ABD problem presented in Annexure 3 is extended to capture the LD-ABD problem. For capturing the problem features of LD-ABD in the numerical problem, the following data are provided:

- Number of buses increased from 15 to 20 and the required data for these new additional buses is as follows:

\begin{tabular}{|c|c|c|c|c|}
\hline Sl. No. & $\begin{array}{l}\text { New Bus } \\
\text { (Route) No. }\end{array}$ & $\begin{array}{l}\text { Starting Terminus } \\
(\mathrm{ST})\end{array}$ & $\begin{array}{l}\text { Ending Terminus } \\
(\mathrm{ET})\end{array}$ & $\begin{array}{l}\text { Fuel Cost } \\
\text { Per KM }\end{array}$ \\
\hline 1 & R16 & BTL & BBS & 10 \\
\hline 2 & R17 & SBS & JPN & 12 \\
\hline 3 & R18 & CMT & BTL & 10 \\
\hline 4 & R19 & JPN & BBS & 12 \\
\hline 5 & R20 & BTL & JPN & 11 \\
\hline
\end{tabular}

- Possible to close 2 exiting depots with immediate requirement of closing only one depot. To capture this requirement, the depot wise salvage cost, which is due to closing the possible depot, is given as follows:

\begin{tabular}{|l|l|l|l|l|l|}
\hline $\begin{array}{l}\text { S1. } \\
\text { No. }\end{array}$ & $\begin{array}{l}\text { Existing } \\
\text { Depot Code }\end{array}$ & $\begin{array}{l}\text { Existing } \\
\text { Depot Name }\end{array}$ & $\begin{array}{l}\text { Existing Depot } \\
\text { Capacity }\end{array}$ & $\begin{array}{l}\text { Possible Depot } \\
\text { to Close }\end{array}$ & $\begin{array}{l}\text { Salvage Cost in Indian } \\
\text { Rupees due to Closing } \\
\text { Depot }\end{array}$ \\
\hline 1. & D1 & Depot 1 & 3 & Yes & 180000 \\
\hline 2. & D2 & Depot 2 & 7 & No & 0 \\
\hline 3. & D3 & Depot 3 & 5 & Yes & 200000 \\
\hline
\end{tabular}

- Possible to open four new depots with immediate requirements of opening 2 new depots only. For addressing this specific requirement, the new depot wise name of the depot along with depot code, fixed cost, and capacity is given as follows:

\begin{tabular}{|l|l|l|l|l|}
\hline $\begin{array}{l}\text { S1. } \\
\text { No. }\end{array}$ & $\begin{array}{l}\text { New Depot } \\
\text { Code }\end{array}$ & $\begin{array}{l}\text { New Depot } \\
\text { Name }\end{array}$ & $\begin{array}{l}\text { New Depot } \\
\text { Capacity }\end{array}$ & $\begin{array}{l}\text { Fixed Cost in Indian Rupees due } \\
\text { to Opening Depot }\end{array}$ \\
\hline 1. & D4 & Depot 4 & 10 & 175000 \\
\hline 2. & D5 & Depot 5 & 8 & 100000 \\
\hline 3. & D6 & Depot 6 & 10 & 150000 \\
\hline 4. & D7 & Depot 7 & 9 & 120000 \\
\hline
\end{tabular}

- Due to increase in the number of buses with new terminus (last two rows indicates new terminus) and a set possible new depots for LD-ABD problem, the date on distance between (Existing and New) Starting/Ending Terminus and Depots (existing and New Depots) is required as follows:

\begin{tabular}{|l|l|c|c|c|c|c|c|c|}
\hline \multirow{2}{*}{$\begin{array}{l}\text { Terminus } \\
\text { Code }\end{array}$} & Terminus Name & \multicolumn{7}{|c|}{ Distance from 'Terminus' to the Depot } \\
\cline { 3 - 9 } & & D1 & D2 & D3 & D4 & D5 & D6 & D7 \\
\hline BBS & Bangalore Bus Station & 10.2 & 9.0 & 11.0 & 8.5 & 7.0 & 9.0 & 11.0 \\
\hline CMT & City Market & 5.0 & 7.0 & 4.0 & 6.0 & 5.0 & 5.4 & 4.0 \\
\hline GNR & Gandhi Nagar & 9.4 & 4.0 & 7.6 & 8.0 & 6.5 & 8.5 & 7.0 \\
\hline MBS & Malleswaram Bus Station & 12.0 & 5.8 & 6.3 & 8.5 & 6.5 & 7.5 & 8.0 \\
\hline SBS & Shivajinagar Bus Station & 8.0 & 10.0 & 7.5 & 6.5 & 6.0 & 7.5 & 9.2 \\
\hline SNR & Srinagar & 5.0 & 5.4 & 9.0 & 8.0 & 6.2 & 7.3 & 4.2 \\
\hline JPN & JP Nagar & 9.0 & 10.0 & 6.0 & 7.5 & 8.5 & 8.0 & 5.7 \\
\hline BTL & BTM Layout & 8.0 & 9.0 & 6.5 & 9.0 & 7.0 & 7.5 & 6.3 \\
\hline
\end{tabular}

